\title{
Ligand Substituent Effects in Manganese Pyridinophane Complexes: Implications for Oxygen-Evolving Catalysis
}

Song Xu, ${ }^{\dagger}$ Lukas Bucinsky, ${ }^{\ddagger}$ Martin Breza, ${ }^{\ddagger} J$. Krzystek, ${ }^{\S}$ Chun-Hsing Chen, ${ }^{\dagger}$ Maren Pink, ${ }^{\dagger}$ Joshua Telser, and Jeremy M. Smith ${ }^{*}+$

${ }^{\dagger}$ Department of Chemistry, Indiana University Bloomington, Bloomington, Indiana 47405-7102, United States

${ }^{\ddagger}$ Institute of Physical Chemistry and Chemical Physics, Faculty of Chemical and Food Technology, Slovak University of Technology, Radlinského 9, SK-81237 Bratislava, Slovakia.

$\S$ National High Magnetic Field Laboratory, Florida State University, Tallahassee, Florida 32310, United States.

I Department of Biological, Chemical and Physical Sciences, Roosevelt University, Chicago, Illinois 60605 United States.

Dedicated to Professor Dr. Karl Wieghardt on the occasion of his $75^{\text {th }}$ birthday anniversary 


\section{Abstract:}

A series of $\mathrm{Mn}(\mathrm{II})$ complexes of differently substituted pyridinophane ligands, $\left(\mathrm{Py}_{2} \mathrm{NR}_{2}\right) \mathrm{MnCl}_{2}$ $\left(\mathrm{R}={ }^{\mathrm{i}} \mathrm{Pr}, \mathrm{Cy}\right)$ and $\left[\left(\mathrm{Py}_{2} \mathrm{NR}_{2}\right) \mathrm{MnF}_{2}\right]\left(\mathrm{PF}_{6}\right)\left(\mathrm{R}={ }^{\mathrm{i}} \mathrm{Pr}, \mathrm{Cy},{ }^{\mathrm{t}} \mathrm{Bu}\right)$ are synthesized and characterized. The electrochemical properties of these complexes are investigated by cyclic voltammetry, along with those of previously reported $\left(\mathrm{Py}_{2} \mathrm{~N}^{t} \mathrm{Bu}_{2}\right) \mathrm{MnCl}_{2}$ and the $\mathrm{Mn}$ (III) complex $\left[\left(\mathrm{Py}_{2} \mathrm{NMe}_{2}\right) \mathrm{MnF}_{2}\right]\left(\mathrm{PF}_{6}\right)$. The electronic structure of this and other $\mathrm{Mn}(\mathrm{III})$ complexes is probed experimentally and theoretically, respectively by high-frequency and -field electron paramagnetic resonance (HFEPR) spectroscopy and by ab initio quantum chemical theory (QCT). These studies showed the complexes to contain relatively typical six-coordinate Mn(III). The catalytic activity of these complexes towards both $\mathrm{H}_{2} \mathrm{O}_{2}$ disproportionation and $\mathrm{H}_{2} \mathrm{O}$ oxidation has also been investigated. The rate of $\mathrm{H}_{2} \mathrm{O}_{2}$ disproportionation decreases with increasing substituent size. Some of these complexes are active for electrocatalytic $\mathrm{H}_{2} \mathrm{O}$ oxidation, however this activity cannot be rationalized in terms of simple electronic or steric effects.
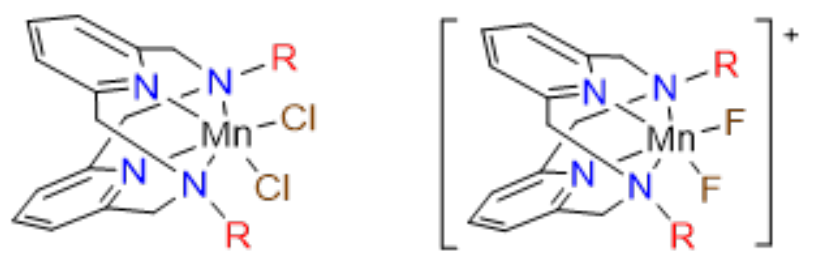

$\mathrm{R}=\mathrm{Me},{ }^{\mathrm{i}} \mathrm{Pr}, \mathrm{Cy},{ }^{\mathrm{t}} \mathrm{Bu}$ : reactivity tuning 


\section{Introduction:}

An attractive strategy for meeting the dramatically increasing demand of clean and renewable energy is to use hydrogen gas as the energy source, which can be obtained from splitting of $\mathrm{H}_{2} \mathrm{O}$ to $\mathrm{H}_{2}$ and $\mathrm{O}_{2} \cdot{ }^{1-3} \mathrm{H}_{2} \mathrm{O}$ is split by Nature under mild conditions using natural oxygenic photosynthesis, which is achieved by the Oxygen Evolving Center (OEC) of Photosystem II. The active site of $\mathrm{OEC}$ has been characterized as a $\mathrm{Mn} 4 \mathrm{Ca}$ cluster through spectroscopic, $\mathrm{X}$-ray diffraction (XRD), and computational studies. ${ }^{4-7}$ Mechanistic investigations suggest that the product $\mathrm{O}-\mathrm{O}$ bond is formed at higher manganese oxidation states, which are accessed via a series of proton coupled electron transfer steps, but detailed information on/about the structure and electron configuration of the transient state in which $\mathrm{O}-\mathrm{O}$ coupling occurs is still lacking. ${ }^{5}$

To better understand this natural $\mathrm{H}_{2} \mathrm{O}$ splitting process, numerous functional and structural model complexes have been synthesized and investigated. ${ }^{1,8}$ Due to Mn being at the active site of the OEC, Mn-based water oxidizing complexes are of particular interest. ${ }^{5}$ While a number of biomimetic/bio-inspired di- and multi-nuclear Mn water oxidation catalysts have been reported, mononuclear manganese catalysts for water oxidation catalyst are rare. ${ }^{8}$ As well as being more synthetically accessible, mononuclear complexes have the potential for relatively straightforward delineation of structure/activity relationships on water oxidation reactivity. Previously our group reported one such complex, $\left(\mathrm{Py}_{2} \mathrm{~N}^{t} \mathrm{Bu}\right)_{2} \mathrm{MnBr}_{2} \quad\left(\mathrm{Py}_{2} \mathrm{~N}^{t} \mathrm{Bu} 2\right.$ is the $N, N^{\prime}$-di-tert-butyl-2,11diaza[3,3](2,6)-pyridinophane ligand), which catalyzes $\mathrm{H}_{2} \mathrm{O}$ oxidation to $\mathrm{O}_{2}$ at ca. $-1.5 \mathrm{~V}$ vs NHE. Since control experiments did not find evidence for the formation of nanoparticulate or heterogeneous catalysts, water oxidation catalysis is likely homogeneous in nature. ${ }^{9}$ Interestingly, replacing the tert-butyl ligand substituent in $\left(\mathrm{Py}_{2} \mathrm{~N}^{t} \mathrm{Bu}\right)_{2} \mathrm{MnBr} 2$ with hydrogen or 
methyl groups, respectively to give $\left(\mathrm{Py}_{2} \mathrm{NH}_{2}\right) \mathrm{MnBr}_{2}$ and $\left(\mathrm{Py}_{2} \mathrm{NMe}_{2}\right) \mathrm{MnBr}_{2}$, results in loss of water oxidation activity; however these complexes were found to catalyze $\mathrm{H}_{2} \mathrm{O}_{2}$ disproportionation to $\mathrm{H}_{2} \mathrm{O}$ and $\mathrm{O}_{2} \cdot{ }^{9-10}$ The latter complexes are thus functional models of the nonheme type II, Mn-containing catalases (Mn-CAT), which perform this reaction in a broad range of microorganisms. ${ }^{11}$

In addition to $\mathrm{H}_{2} \mathrm{O}$ oxidation and $\mathrm{H}_{2} \mathrm{O}_{2}$ disproportionation, the $\mathrm{Py}_{2} \mathrm{NR}_{2}$ ligand framework has been shown to support metal complexes that catalyze a variety of other reactions. For example,

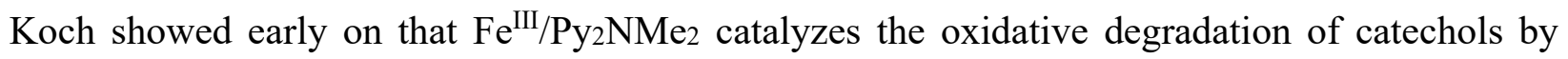
$\mathrm{O}_{2 .}{ }^{12-13}$ More recently, Mirica reported carbon-carbon and carbon-heteroatom bonds formation catalyzed by $\mathrm{Ni}^{\mathrm{III}} / \mathrm{Py}_{2} \mathrm{~N}^{\mathrm{t}} \mathrm{Bu} 2 .{ }^{14}$ In addition to catalysis, spin crossover was also observed for a $\mathrm{Fe}^{\mathrm{II} / \mathrm{Py}} \mathrm{N}^{\mathrm{t}} \mathrm{Bu}_{2}$ complex. ${ }^{15}$ The ability to modify the $\mathrm{R}$ groups of $\mathrm{Py}_{2} \mathrm{NR}_{2}$ ligands allows the catalytic behavior of their metal complexes to be tuned. For example, Cho reported that aldehyde deformylation catalyzed by $\mathrm{Ni}^{\mathrm{II}} / \mathrm{Py}_{2} \mathrm{NR}_{2}$ can be significantly accelerated when switching from $\mathrm{R}$ $=$ tert-butyl to cyclohexyl, which they attribute to a reduction in bulkiness. ${ }^{16}$ Since we previously demonstrated that the catalytic reactivity of $\mathrm{Mn} / \mathrm{Py}_{2} \mathrm{NR}_{2}$ towards $\mathrm{O}_{2}$ evolution is influenced by the pyridinophane ligand substituent, we became interested in systematically delineating the relationship between the pyridinophane ligand substituents and the reactivity of their manganese complexes.

We report here the synthesis and structural characterization of $\left(\mathrm{Py}_{2} \mathrm{NR}_{2}\right) \mathrm{MnCl}_{2}\left(\mathrm{R}={ }^{\mathrm{i}} \mathrm{Pr} 2, \mathrm{Cy}\right.$ 3) and $\left[\left(\mathrm{Py}_{2} \mathrm{NR}_{2}\right) \mathrm{MnF}_{2}\right]\left(\mathrm{PF}_{6}\right)\left(\mathrm{R}={ }^{\mathrm{i}} \operatorname{Pr} 6, \mathrm{Cy} 7,{ }^{\mathrm{t}} \mathrm{Bu} 8\right)$ complexes (Scheme 1). Along with structural, electrochemical and catalytic properties of previously reported $\left(\mathrm{Py}_{2} \mathrm{NMe}_{2}\right) \mathrm{MnCl}_{2} \mathbf{1}$, $\left[\left(\mathrm{Py}_{2} \mathrm{NMe}_{2}\right) \mathrm{MnF}_{2}\right]^{+} \mathbf{5}$ complexes, ${ }^{17}$ we have investigated the effect of the $N$-substituents on their catalytic reactivity of these complexes towards $\mathrm{H}_{2} \mathrm{O}_{2}$ disproportionation and $\mathrm{H}_{2} \mathrm{O}$ oxidation. 
Scheme 1. $\left(\mathrm{Py}_{2} \mathrm{NR}_{2}\right) \mathrm{MnCl}_{2},\left[\left(\mathrm{Py}_{2} \mathrm{NR}_{2}\right) \mathrm{Mn}(\mathrm{NCMe})_{2}\right]^{2+}$ and $\left[\left(\mathrm{Py}_{2} \mathrm{NR}_{2}\right) \mathrm{MnCl}_{2}\right]^{+}$complexes in this work.
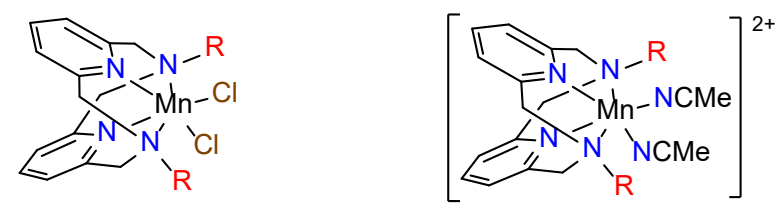

$$
\begin{gathered}
\left(\mathrm{Py}_{2} \mathrm{NR}_{2}\right) \mathrm{MnCl}_{2} \\
\mathrm{R}=\mathrm{Me}(\mathbf{1}),{ }^{\mathrm{i}} \operatorname{Pr}(\mathbf{2}), \\
\mathbf{3}),{ }^{\mathrm{t}} \mathrm{Bu}(\mathbf{4})
\end{gathered}
$$$$
\left[\left(\mathrm{Py}_{2} \mathrm{NR}_{2}\right) \mathrm{Mn}(\mathrm{NCMe})\right]^{2+}
$$$$
\mathrm{R}=\operatorname{Me}\left(\mathbf{1}^{\prime}\right),{ }^{\mathrm{i}} \operatorname{Pr}\left(\mathbf{2}^{\prime}\right),
$$

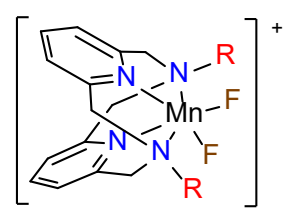

$$
\begin{gathered}
{\left[\left(\mathrm{Py}_{2} \mathrm{NR}_{2}\right) \mathrm{MnF}_{2}\right]^{+}} \\
\mathrm{R}=\mathrm{Me}(\mathbf{5}),{ }^{\mathrm{i} P r}(\mathbf{6}), \\
\mathrm{Cy}\left(\mathbf{7}^{\mathrm{i}}\right),{ }^{\mathrm{i}} \mathrm{Bu}(\mathbf{8})
\end{gathered}
$$

We have also elucidated the electronic structure of these complexes though a combination of experiment and theory, primarily high-frequency and -field electron paramagnetic resonance (HFEPR) spectroscopy and quantum chemical theory (QCT) calculations. While density functional theory $(\mathrm{DFT})$ calculations on $\left[\left(\mathrm{Py}_{2} \mathrm{NMe}_{2}\right) \mathrm{MnF}_{2}\right]\left(\mathrm{PF}_{6}\right)(5)$ were reported by Albela et al. ${ }^{17}$ herein a multi-configurational treatment allows for a more accurate assessment of the electronic structure description and zero-field splitting (ZFS). ${ }^{18-19}$ Therefore, we used the complete active space self-consistent field (CASSCF) method ${ }^{18,20-22}$ (treating spin-orbit coupling $(\mathrm{SOC})$ effects perturbatively $\left.{ }^{23}\right)$ to investigate the electronic structure of $\left[\left(\mathrm{Py}_{2} \mathrm{NR}_{2}\right) \mathrm{MnX}_{2}\right]^{+}(\mathrm{X}=$ $\mathrm{F}^{-}, \mathrm{Cl}^{-}$), including n-electron valence (electron) second-order perturbation theory (NEVPT2) ${ }^{24-26}$ to account for dynamic electron correlation effects and multi-reference configuration interaction $(\mathrm{MRCI})^{18,20,27}$ to assess the spin-spin contribution, as well as DFT level for completeness. These results provide an experimental calibration for a similar computational investigation of the 
hydroxido complex, $\left[\left(\mathrm{Py}_{2} \mathrm{~N}^{t} \mathrm{Bu} 2\right) \mathrm{Mn}(\mathrm{OH})_{2}\right]^{+}$which has been proposed as an intermediate in electrocatalytic water oxidation by a Mn pyridinophane complex. ${ }^{28-29}$

\section{Results and Discussion}

Preparation and Characterization of $\left(\mathrm{Py}_{2} \mathrm{NR}_{2}\right) \mathrm{MnCl}_{2}$ and $\left[\left(\mathrm{Py}_{2} \mathrm{NR}_{2}\right) \mathrm{MnF}_{2}\right]^{+}\left(\mathrm{R}=\mathrm{Me},{ }^{\mathrm{i}} \mathrm{Pr}\right.$, $\left.\mathbf{C y},{ }^{\mathbf{t}} \mathbf{B u}\right)$

Similarly to the previously reported bromide analogues, $\left(\mathrm{Py}_{2} \mathrm{NR}_{2}\right) \mathrm{MnBr}_{2}\left(\mathrm{R}=\mathrm{H}, \mathrm{Me},{ }^{\mathrm{t}} \mathrm{Bu}\right),{ }^{9-10}$ complexes $1-4$ were prepared by treating the appropriate $\mathrm{Py}_{2} \mathrm{NR}_{2}$ ligand with anhydrous $\mathrm{MnCl}_{2}$ in acetonitrile solution (Scheme 2a). The pale yellow $\left(\mathrm{Py}_{2} \mathrm{NR}_{2}\right) \mathrm{MnCl}_{2}$ products were characterized by single crystal X-ray diffraction and high resolution mass spectrometry. Complex $\mathbf{2}$ can be converted to the acetonitrile-solvated complex, $\mathbf{2}^{\prime}$, by treating $\mathbf{2}$ with 2 equiv of TlPF 6 in acetonitrile solution, as previously reported for $\mathbf{1}^{\prime}$ and $\mathbf{4}^{\prime} .^{9-10}$ Complex $\mathbf{2}^{\prime}$ has also been characterized by single crystal X-ray diffraction.

The Mn(III) difluoride complex 6 can be prepared in an analogous manner to the synthesis of 5, ${ }^{17}$ wherein a mixture of $\mathrm{Py}_{2} \mathrm{~N}^{\mathrm{i}} \mathrm{Pr}_{2}$ and $\mathrm{MnF}_{3}$ is gently heated in MeOH. Unfortunately, this protocol does not work for the synthesis of complexes $\mathbf{7}$ and $\mathbf{8}$, presumably due to the poor methanol solubility of the ligands, with their bulky aliphatic substituents. However, these complexes can be obtained by the fluorination of $\mathbf{3}^{\prime}$ and $\mathbf{4}^{\prime}$ with $\mathrm{XeF}_{2}$ in $\mathrm{MeCN}$, similarly to the preparation of other organometallic fluoride complexes. ${ }^{30-31}$ Complex 6 can also be prepared by this method. Complexes 6, 7, and $\mathbf{8}$ were isolated as dark orange crystals and characterized by single crystal X-ray diffraction and high resolution mass spectrometry. It is worth noting that $\mathrm{XeF}_{2}$ is typically a two-electron oxidant that transfers two fluorine atoms to the metal, ${ }^{31}$ however only the one-electron oxidized products, 6, 7, and $\mathbf{8}$ were obtained from these fluorination 
reactions (Scheme 2b). We therefore propose that the $\operatorname{Mn}(\mathrm{III})$ complexes $(\mathbf{6}, \mathbf{7 , 8})$ are generated through comproportionation of the two-electron oxidized $\mathrm{Mn}(\mathrm{IV})$ complexes $\left[\left(\mathrm{Py}_{2} \mathrm{NR}_{2}\right) \mathrm{MnF}_{2}\right]^{2+}$ (formed by two-electron oxidation by $\left.\mathrm{XeF}_{2}\right)$ and the $\mathrm{Mn}(\mathrm{II})$ reagents, $\left[\left(\mathrm{Py}_{2} \mathrm{NR}_{2}\right) \mathrm{Mn}(\mathrm{NCMe})_{2}\right]^{2+}$.

Scheme 2. Synthesis of the (a) $\mathrm{Py}_{2} \mathrm{NR}_{2} \mathrm{MnCl}_{2}$ and (b) $\left[\mathrm{Py}_{2} \mathrm{NR}_{2} \mathrm{MnF}_{2}\right]\left(\mathrm{PF}_{6}\right)$ complexes

a)

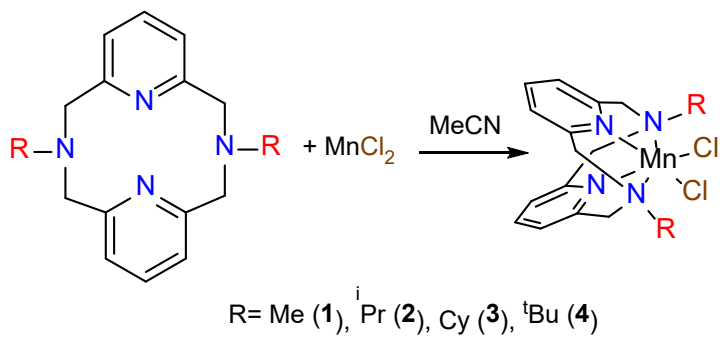

b)

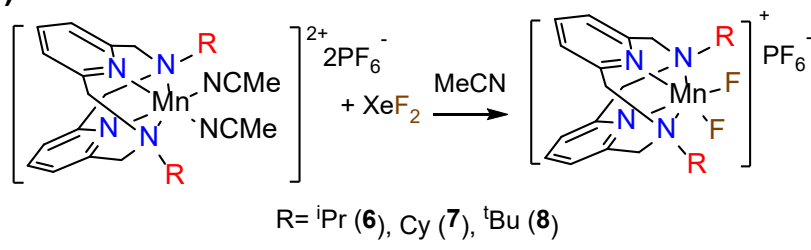

The UV-vis spectra of complex 6 - 8 each show a band around $500 \mathrm{~nm}$ that has a low extinction coefficient (Figures S4 - S6) similarly to observations for $5 .{ }^{17}$ The high spin state of $\operatorname{Mn}(\mathrm{III})\left(3 \mathrm{~d}^{4}, S=2\right)$ is confirmed by the magnetic susceptibility of $\mathbf{8}$ ( $\mu_{\mathrm{eff}}=5.20 \mu_{\mathrm{B}}$ determined by Evans' method), which consistent with the theoretical value calculated for $S=2$ ( $\mu_{\mathrm{eff}}=4.90$ $\mu_{\mathrm{B}) .}$

\section{Molecular structures of $\left[\left(\mathrm{Py}_{2} \mathrm{NR}_{2}\right) \mathrm{Mn}(\mathrm{NCMe})_{2}\right]^{2+}$ and $\left[\left(\mathrm{Py}_{2} \mathrm{NR}_{2}\right) \mathrm{MnF}_{2}\right]^{+}\left(\mathrm{R}=\mathrm{Me},{ }^{\mathrm{i} P r}, \mathrm{Cy}\right.$,}

tBu)

X-ray quality crystals of $\mathbf{1}^{\prime}, \mathbf{2}^{\prime}, \mathbf{4}^{\prime}, \mathbf{3}, \mathbf{6}, 7$, and $\mathbf{8}$ were obtained by slow diffusion of diethyl ether into concentrated acetonitrile solution at ambient temperature. Representations of the molecular structures are shown in Figures 1 and 2, with selected bond distances and angles given 
in Tables 1 and 2. We were unable to isolate crystals of $\mathbf{3}^{\prime}$ suitable for X-ray diffraction studies, although its chloride analogue, 3 was successfully characterized by single crystal X-ray diffraction, providing data for comparison with the acetonitrile complexes $\left(\mathbf{1}^{\prime}, \mathbf{2}^{\prime}\right.$, and $\left.\mathbf{4}^{\prime}\right)$.

According to structural data summarized in Table 1, the structures of the Mn(II) complexes, 1', $\mathbf{2}^{\prime}$, and $\mathbf{4}^{\prime}$ are generally similar to the previous reported analogues, $\mathbf{1}$ and the bromido series $\left(\mathrm{Py}_{2} \mathrm{NR}_{2}\right) \mathrm{MnBr}_{2}\left(\mathrm{R}=\mathrm{Me},{ }^{\mathrm{t}} \mathrm{Bu}\right) .{ }^{9-10,} 17$ Specifically, these mononuclear complexes all exhibit pseudo-octahedral geometries with an equatorial plane consisting of two acetonitrile ligands and two pyridine donors, with the amines occupying the axial positions. The geometry of the pyridinophane ligand ensures that the acetonitrile (or other ancillary) ligands are cis with respect to other with the two pyridines trans to the acetonitrile ligands. Complex $\mathbf{3}$ has a similar structure to $\mathbf{1}^{\prime}, \mathbf{2}^{\prime}, \mathbf{4}^{\prime}$, although the $\mathrm{N}($ amine)-Mn-N(amine) and $\mathrm{N}$ (pyridine)-Mn-N(pyridine) bond angles are significantly smaller for $\mathbf{3}$, likely a consequence of the larger chlorido ligands. This response to the change in ancillary ligands suggests the pyridinophane ligand has flexibility in its binding mode. It is worth noting that similar bond angles involving the pyridinophane ligand are observed for $\mathbf{1}$, which has been reported previously. ${ }^{17}$

The data in Table 1 suggests that the pyridinophane substituents have a significant effect on the Mn-amine distances in the $\left[\left(\mathrm{Py}_{2} \mathrm{NR}_{2}\right) \mathrm{Mn}(\mathrm{NCMe})_{2}\right]^{2+}$ complexes. For example, the $\mathrm{Mn}$ $\mathrm{N}$ (amine) distance in $\mathbf{4}^{\prime}$ is $0.103 \AA$ longer than the corresponding distance in $\mathbf{1}^{\prime}$. By contrast, the complexes show no significant difference in Mn-N(pyridine) and Mn-N(acetonitrile) distances. Assuming that the chloride ligands in $\mathbf{3}$ do not significantly perturb the other bond lengths, the combined data suggests that the Mn-N(amine) distance increases with increasing bulkiness of the pyridinophane substituent. 
The Mn(III) complexes $\mathbf{6}$ - $\mathbf{8}$ are generally similar in structure to those of the Mn(II) complexes discussed above. Thus, the Mn ions are also coordinated by the tetradentate macrocycle and two fluoride ligands that are cis with respect to other (Table 2). However, the Mn(III) complexes generally have shorter bond lengths, which is attributed to the smaller size of the Mn(III) ion. Similarly to $\mathbf{5},{ }^{17} \mathbf{6}-\mathbf{8}$ also show characteristic Jahn-Teller elongations along the axis containing the amine donors, as revealed by $\mathrm{Mn}-\mathrm{N}$ (amine) bond lengths that are significantly longer ( $c a .0 .3$ $\AA$ ) than the Mn-N(pyridine) distances. Interestingly, the Mn-N(amine) distances for 5 are significantly shorter than for $\mathbf{6}-\mathbf{8}$, which are similar in magnitude, suggesting that this distance is not strongly dependent on the size of the substituent, in contrast to the $\mathrm{Mn}(\mathrm{II})$ complexes.

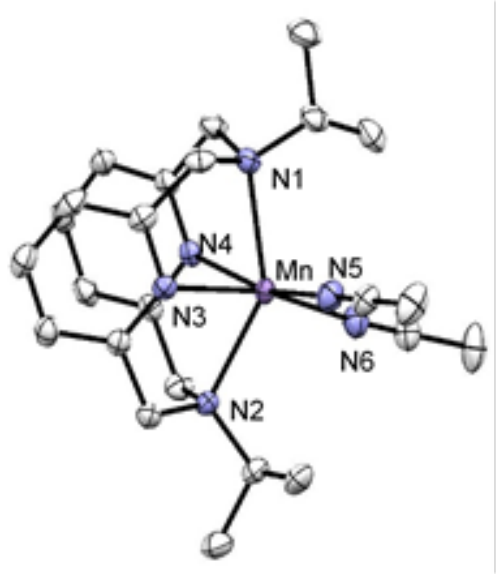

(2')

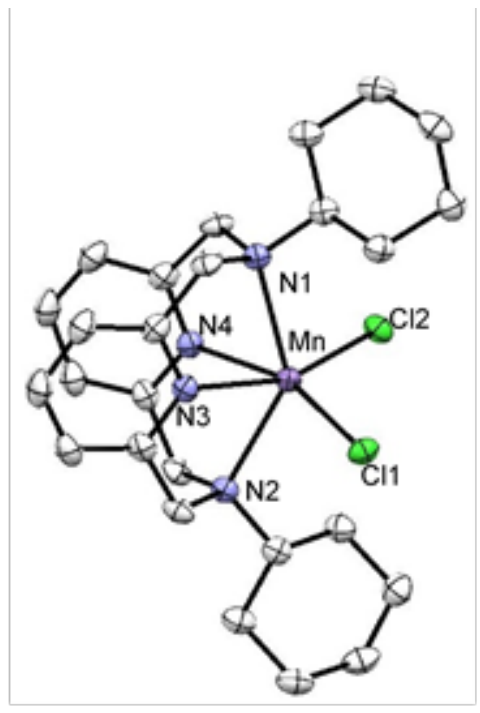

(3)

Figure 1. ORTEPs of complexes $\mathbf{2}^{\prime}$ and 3 (50\% ellipsoids, hydrogen atoms and $\mathrm{PF}_{6}$ anions are omitted for clarity). Selected bond lengths ( $\AA$ ) and angles $\left(^{\circ}\right)$ for 3: Mn-N1 2.444(2); Mn-N2 2.444(2); Mn-N3 2.273(2); Mn-N4 2.273(2); Mn-C11 2.4350(8); Mn-Cl2 2.4350(8); N1-Mn-N2 138.42(2); N3-Mn-N4 72.84(13); Cl1-Mn-C12 104.54. 


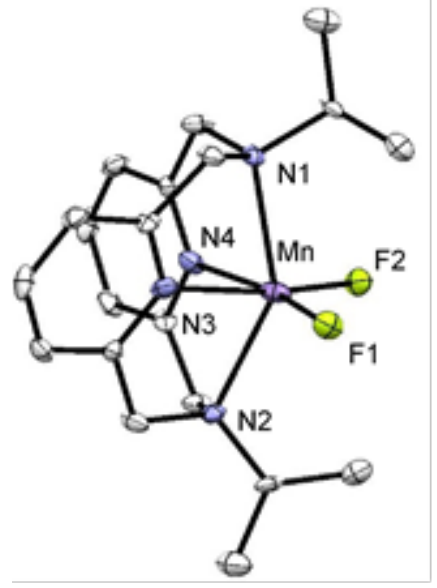

(6)

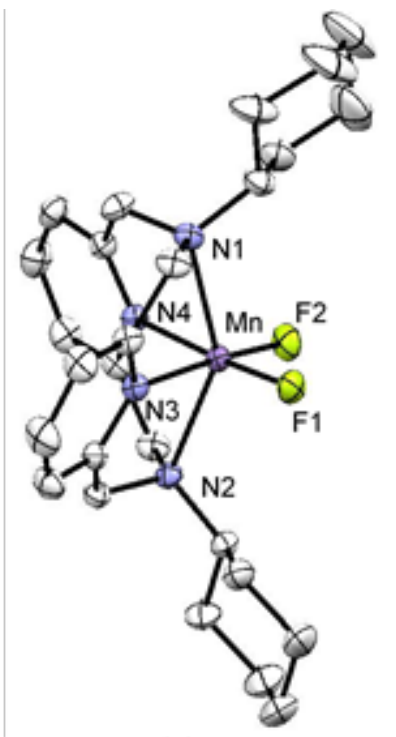

(7)

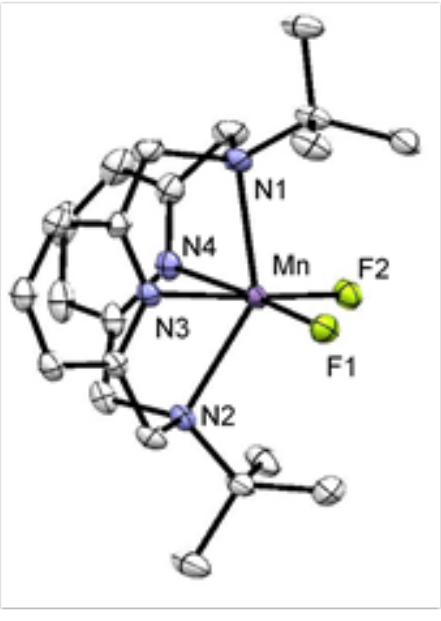

(8)

Figure 2. ORTEPs of complexes 6, 7, and $\mathbf{8}$ (50\% ellipsoids, hydrogen atoms and $\mathrm{PF}_{6}$ anions are omitted for clarity). 
Table 1. Selected bond lengths $(\AA)$ and angles $\left({ }^{\circ}\right)$ of $\mathbf{1}^{\prime}, \mathbf{2}^{\prime}$, and $\mathbf{4}^{\prime}$.

\begin{tabular}{|c|c|c|c|}
\hline & \multicolumn{3}{|c|}{$\left[\mathrm{Py}_{2} \mathrm{NR}_{2} \mathrm{Mn}^{\mathrm{II}}(\mathrm{NCMe})_{2}\right]^{2+}$} \\
\hline & $\operatorname{Me}\left(\mathbf{1}^{\prime}\right)^{17}$ & ${ }^{\mathrm{i}} \operatorname{Pr}\left(\mathbf{2}^{\prime}\right)$ & ${ }^{t} \mathrm{Bu}\left(4^{\prime}\right)^{9}$ \\
\hline Mn-N1 & $2.327(2)$ & $2.357(1)$ & $2.455(2)$ \\
\hline $\mathrm{Mn}-\mathrm{N} 2$ & $2.328(2)$ & $2.365(2)$ & $2.415(2)$ \\
\hline Mn-N3 & $2.198(2)$ & $2.198(1)$ & $2.236(2)$ \\
\hline Mn-N4 & $2.213(2)$ & $2.216(1)$ & $2.165(2)$ \\
\hline Mn-N5 & $2.174(2)$ & $2.191(1)$ & $2.152(2)$ \\
\hline Mn-N6 & $2.184(2)$ & $2.208(2)$ & $2.210(2)$ \\
\hline N1-Mn-N2 & $143.44(6)$ & $143.52(5)$ & $143.41(6)$ \\
\hline N3-Mn-N4 & $77.61(6)$ & $77.58(4)$ & $75.10(7)$ \\
\hline N5-Mn-N6 & $94.54(7)$ & $90.74(5)$ & $96.91(8)$ \\
\hline
\end{tabular}


Table 2. Selected bond lengths $(\AA)$ and angles $\left(^{\circ}\right)$ of 5, 6, 7, and $\mathbf{8}$.

\begin{tabular}{|c|c|c|c|c|}
\hline & \multicolumn{4}{|c|}{$\left[\mathrm{Py}_{2} \mathrm{NR}_{2} \mathrm{Mn}^{\mathrm{III}} \mathrm{F}_{2}\right]^{+}$} \\
\hline & $\operatorname{Me}(\mathbf{5})^{17}$ & ${ }^{\mathrm{i}} \operatorname{Pr}(\mathbf{6})$ & Cy (7) & ${ }^{t} \mathrm{Bu}(8)$ \\
\hline Mn-N1 & $2.274(2)$ & $2.328(4)$ & $2.314(2)$ & $2.337(1)$ \\
\hline $\mathrm{Mn}-\mathrm{N} 2$ & $2.278(2)$ & $2.328(4)$ & $2.310(2)$ & $2.332(2)$ \\
\hline $\mathrm{Mn}-\mathrm{N} 3$ & $2.024(2)$ & $2.089(3)$ & $2.002(2)$ & $2.018(2)$ \\
\hline Mn-N4 & $2.020(2)$ & $2.089(3)$ & $2.009(2)$ & $2.008(1)$ \\
\hline $\mathrm{Mn}-\mathrm{F} 1$ & $1.805(2)$ & $1.754(3)$ & $1.806(2)$ & $1.805(1)$ \\
\hline Mn-F2 & $1.801(2)$ & $1.754(3)$ & $1.811(1)$ & $1.810(1)$ \\
\hline N1-Mn-N2 & $147.03(8)$ & $145.3(2)$ & $145.14(8)$ & $145.37(5)$ \\
\hline N3-Mn-N4 & $77.07(8)$ & $79.61(8)$ & $86.76(8)$ & $85.72(6)$ \\
\hline F1-Mn-F2 & $94.89(8)$ & $100.58(7)$ & $92.94(7)$ & $95.77(5)$ \\
\hline
\end{tabular}




\section{High-Frequency and -Field EPR}

Given that $\mathrm{Mn}(\mathrm{III})$ complexes in general are highly amenable to study by HFEPR, ${ }^{32-35}$ and the pyridinophane complex $\left[\left(\mathrm{Py}_{2} \mathrm{NMe}_{2}\right) \mathrm{MnF}_{2}\right]\left(\mathrm{PF}_{6}\right)$ (here, 5) in particular had been previously investigated experimentally by HFEPR, as well as computationally, by Albela et al., ${ }^{17}$ we decided to confirm and extend those studies. HFEPR investigation of $\mathbf{6}$ was most successful and clearly showed the $S=2$ ground state, with a negative $D$ value, as seen in the HFEPR spectrum and simulations shown in Figure 3. HFEPR spectra of $\mathbf{5}$ gave spin Hamiltonian parameters in agreement with those previously reported and was thus not extensively studied here. In the case of 6, a complete set of multi-frequency spectra was recorded. Analysis of this 2-D fieldfrequency dependence, ${ }^{36}$ shown in Figure 4, gave the full set of spin Hamiltonian parameters, which were similar, but not identical to those of $\mathbf{5}$, showing the sensitivity of ZFS parameters to small structural/electronic changes. Full details are given in the Supporting Information. 


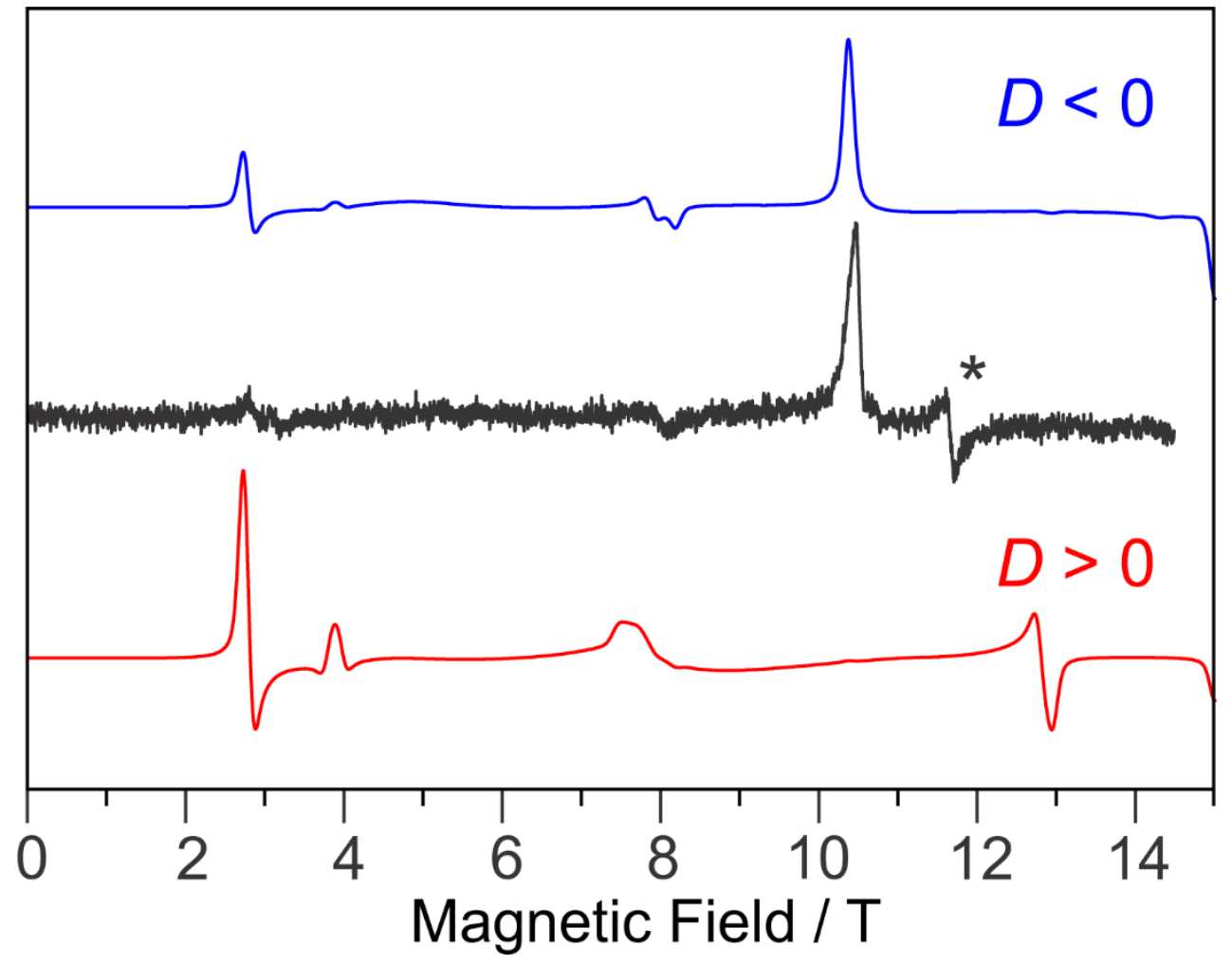

Figure 3. A $633.6 \mathrm{GHz}, 5 \mathrm{~K}$ HFEPR spectrum of $\mathbf{6}$ as a pellet (black trace) with two simulations, using the following spin Hamiltonian parameters: $|D|=3.78 \mathrm{~cm}^{-1} ;|E|=0.064 \mathrm{~cm}^{-1}(E / D=0.02)$; $\boldsymbol{g}=[2.00,2.01,2.02]$. Blue trace: $D<0$; red trace: $D>0$. The resonance at $11.7 \mathrm{~T}$ marked with the asterisk could not be attributed to the $S=2$ spin system under study, and is thus not simulated. 


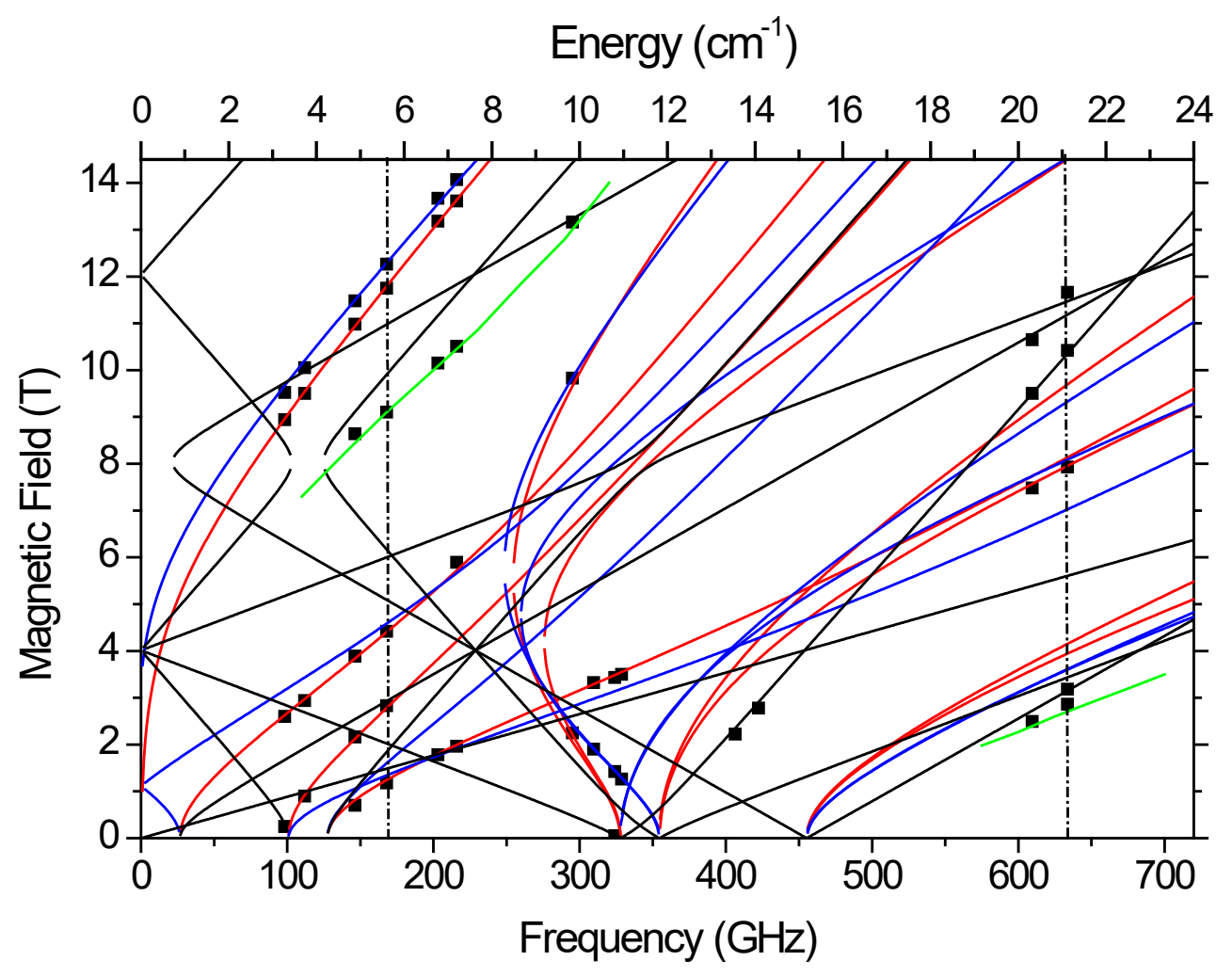

Figure 4. A 2-D map of turning points in the powder spectra of 6 as a function of frequency. The squares are experimental points while the curves are simulations: Red curves: magnetic field $B_{0}$ parallel to the $x$ axis of the ZFS tensor, blue curves: $B_{0} \| y$; black curves $B_{0} \| z$; green curves: offaxis turning points. The simulation parameters were: $|D|=3.79 \mathrm{~cm}^{-1} ;|E|=0.15 \mathrm{~cm}^{-1}(E / D=$ $0.04) ; \boldsymbol{g}=[1.94,2.08,2.02]$. The dashed vertical lines represent the frequencies at which spectra shown in Figs. S14 (lower frequency) and 3 (higher frequency) were recorded.

A LFT analysis of the electronic absorption spectra of $\mathbf{5}$ agreed with Albela et al., but also provided both crystal-field (as defined by Ballhausen) and AOM parameters quantifying the bonding of the pyridinophane ligand. Full details are given in the SI. QCT investigation of several complex cations of general formula $\left[\left(\mathrm{Py}_{2}(\mathrm{NR})_{2}\right) \mathrm{MnX}_{2}\right]^{+}(\mathrm{R}=\mathrm{Me}, \mathrm{Cy} ; \mathrm{X}=\mathrm{F}, \mathrm{Cl}, \mathrm{OH})$ clearly show the spin quintet ground state with the "hole" in $\mathrm{d}_{x y}$ in agreement with the earlier, 
DFT calculations on 5 (Figure 5). ${ }^{17}$ The reported sa-CASSCF $(4,5)$ based calculations lead to $D$ values ranging from $-3.8 \mathrm{~cm}^{-1}$ to $-4.0 \mathrm{~cm}^{-1}$ when taking into account the spin-spin coupling (SSC) interaction (using MRCI) and NEVPT2 dynamic electron correlation effects, where the SSC contribution is about 5 times larger $\left(-0.5 \mathrm{~cm}^{-1}\right)$ than dynamic electron correlation effects $\left(-0.1 \mathrm{~cm}^{-1}\right)$ in the case of the optimized geometries, see Tables S5 and S6 (Supporting Information). ${ }^{37}$ The BLYP DFT method underestimates the $D$ parameter by ca. $1 \mathrm{~cm}^{-1}$, and B3LYP results are even less satisfactory, see Tables S5 and S6 (Supporting Information). Full details of the QCT studies are given in Supporting Information, which also provides frontier B3LYP MO diagrams of complexes of interest (Figure S19). Importantly, the calculations show that $\left[\left(\mathrm{Py}_{2}(\mathrm{NR})_{2}\right) \mathrm{Mn}(\mathrm{OH})_{2}\right]^{+}$, which is proposed as an intermediate in water oxidation, ${ }^{28}$ has the same electronic structure as $\left[\left(\mathrm{Py}_{2}(\mathrm{NR})_{2}\right) \mathrm{MnX}_{2}\right]^{+}(\mathrm{X}=\mathrm{F}, \mathrm{Cl})$. Thus, the properties of the latter complexes are expected to provide a good model for those of $\left[\left(\mathrm{Py}_{2}(\mathrm{NR})_{2}\right) \mathrm{Mn}(\mathrm{OH})_{2}\right]^{+}$, which has so far eluded experimental isolation.

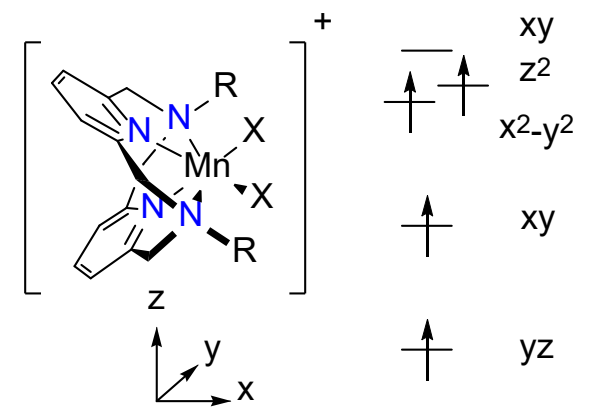

Figure 5. Qualitative d-orbital manifold for $\left[\left(\mathrm{Py}_{2}(\mathrm{NR})_{2}\right) \mathrm{MnX}_{2}\right]^{+}$complexes.

\section{Electrochemical Studies}

The electrochemical properties of $\mathbf{1}-\mathbf{4}$ were investigated in $\mathrm{NBu}_{4} \mathrm{PF}_{6} / \mathrm{MeCN}$, with all potentials referenced to $\mathrm{Fc} / \mathrm{Fc}^{+}$(Table 3). As illustrated by the cyclic voltammogram of 4 (Figure 6), all complexes show one quasi-reversible reductive and one reversible oxidative process, with 
complexes $\mathbf{1}$ and $\mathbf{4}$ showing an additional quasi-reversible oxidative process at higher potential. This second oxidative process is irreversible for $\mathbf{2}$ and $\mathbf{3}$ (Figures S8 - S10).

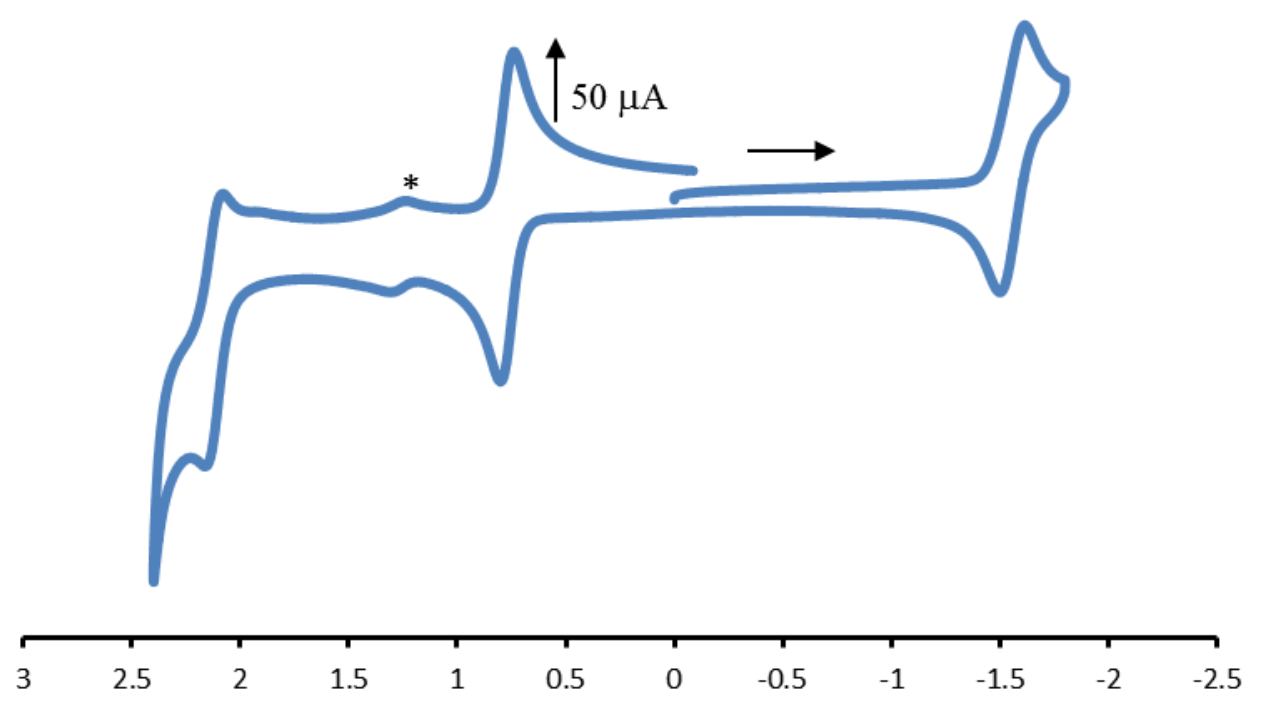

Figure 6. Cyclic voltammogram of 4 recorded at room temperature in $\mathrm{MeCN}$ solution. GC electrode, $0.1 \mathrm{M} \mathrm{NBu}_{4} \mathrm{PF}_{6}$ as electrolyte (scan rate $=100 \mathrm{mV} / \mathrm{s}$ ). * -impurity.

Since the $\mathrm{Zn}$ analogue, $\left[\left(\mathrm{Py}_{2} \mathrm{~N}^{t} \mathrm{Bu} 2\right) \mathrm{Zn}(\mathrm{OTf})(\mathrm{NCMe})\right]^{+}$, shows a reduction event at $c a .-2 \mathrm{~V}$ vs $\mathrm{Fc} / \mathrm{Fc}^{+}$that has been assigned as a ligand-based reduction, ${ }^{38}$ we have likewise assigned the quasireversible reductive processes to ligand-based reduction. The first oxidative wave is assigned to the $\mathrm{Mn}^{\mathrm{III}} / \mathrm{Mn}^{\mathrm{II}}$ couple, which is confirmed through independent synthesis (see below) and the second quasi-reversible oxidation wave is tentatively assigned to the $\mathrm{Mn}^{\mathrm{IV}} / \mathrm{Mn}^{\mathrm{III}}$ couple. The electrochemical data clearly shows the superior ability of $\mathrm{Py}_{2} \mathrm{~N}^{t} \mathrm{Bu} 2$ to stabilize $\mathrm{Mn}$ (III) (Table 3). Notably, the $\mathrm{Mn}^{\mathrm{III}} / \mathrm{Mn}^{\mathrm{II}}$ and $\mathrm{Mn}^{\mathrm{IV}} / \mathrm{Mn}^{\mathrm{III}}$ potentials of these complexes are at a significantly higher potential than for analogous manganese complexes of dimethyl substituted cross-bridged tetraazamacrocycle $\left((\mathrm{BCA}) \mathrm{MnCl}_{2}\right.$ and $(\mathrm{BCE}) \mathrm{MnCl}_{2}$, Figure $\left.\mathrm{S} 12\right)$ : where $E_{1 / 2}\left(\mathrm{Mn}^{\mathrm{III}} / \mathrm{Mn}^{\mathrm{II}}\right)$ is $-0.055 \mathrm{~V}$ for $(\mathrm{BCA}) \mathrm{MnCl}_{2}$ and $-0.174 \mathrm{~V}$ for $(\mathrm{BCE}) \mathrm{MnCl}_{2} ; E_{1 / 2}\left(\mathrm{Mn}^{\mathrm{IV}} / \mathrm{Mn}^{\mathrm{IIII}}\right)$ is $+0.703 \mathrm{~V}$ for (BCA) $\mathrm{MnCl}_{2}$ and $+0.592 \mathrm{~V}$ for $(\mathrm{BCE}) \mathrm{MnCl}_{2}{ }^{39}$ The difference in potentials is likely due to the 
different donor strengths of these macrocycles, all of which create a cis-divacant coordination environment.

Table 3. Redox potentials $\left(E_{1 / 2}\right)$ for $\mathbf{1}-\mathbf{4}\left(\mathrm{vs} \mathrm{Fc} / \mathrm{Fc}^{+}\right)$.

\begin{tabular}{cccc}
\hline & Py $/$ Py & $\mathrm{Mn}^{\mathrm{III}} / \mathrm{Mn}^{\mathrm{II}}$ & $\mathrm{Mn}^{\mathrm{IV}} / \mathrm{Mn}^{\mathrm{III}}$ \\
\hline $\mathbf{1}$ & -2.37 & 0.16 & 1.24 \\
$\mathbf{2}$ & -2.37 & 0.20 & $1.38^{\mathrm{a}}$ \\
$\mathbf{3}$ & -2.32 & 0.21 & $1.29^{\mathrm{a}}$ \\
$\mathbf{4}$ & -2.28 & 0.04 & 1.40 \\
\hline
\end{tabular}

${ }^{\text {a }}$ Irreversible waves, $E_{\mathrm{pa}}$ values are shown.

The reversibility of the first oxidative process observed in the CV of $\mathbf{4}$ has been confirmed by chemical oxidation. Treating 4 with the thianthrenyl cation $\left(\mathrm{Th} \cdot \mathrm{BF}_{4}, E_{1 / 2}=0.86 \mathrm{~V} \text { vs } \mathrm{Fc} / \mathrm{Fc}^{+}\right)^{40}$ results in an immediate color change from pale yellow to dark orange (Scheme 3). The oxidized product is characterized as $\left[\left(\mathrm{Py}_{2} \mathrm{~N}^{t} \mathrm{Bu}\right) \mathrm{MnCl}_{2}\right] \mathrm{BF}_{4}$ (9) by ESI-MS and single crystal X-ray diffraction, with the structure shown in Figure 7. The UV-vis spectrum of 9 shows a band around $500 \mathrm{~nm}$, similarly to the spectroscopically characterized complex $\left[\left(\mathrm{Py}_{2} \mathrm{NMe}\right) \mathrm{MnCl}_{2}\right]^{+}$(Figure S7). ${ }^{17}$ The magnetic susceptibility of $\mathbf{9}$, as measured by Evans' method ( $\mu_{\text {eff }}=5.05 \mu \mathrm{B}$ ), is consistent with high spin $(S=2) \mathrm{Mn}(\mathrm{III})$.

Scheme 3. Formation of $\left[\left(\mathrm{Py}_{2} \mathrm{~N}^{\mathrm{t}} \mathrm{Bu}_{2}\right) \mathrm{Mn}^{\mathrm{III}} \mathrm{Cl}_{2}\right]^{+}$(9) by chemical oxidation of 4 . 

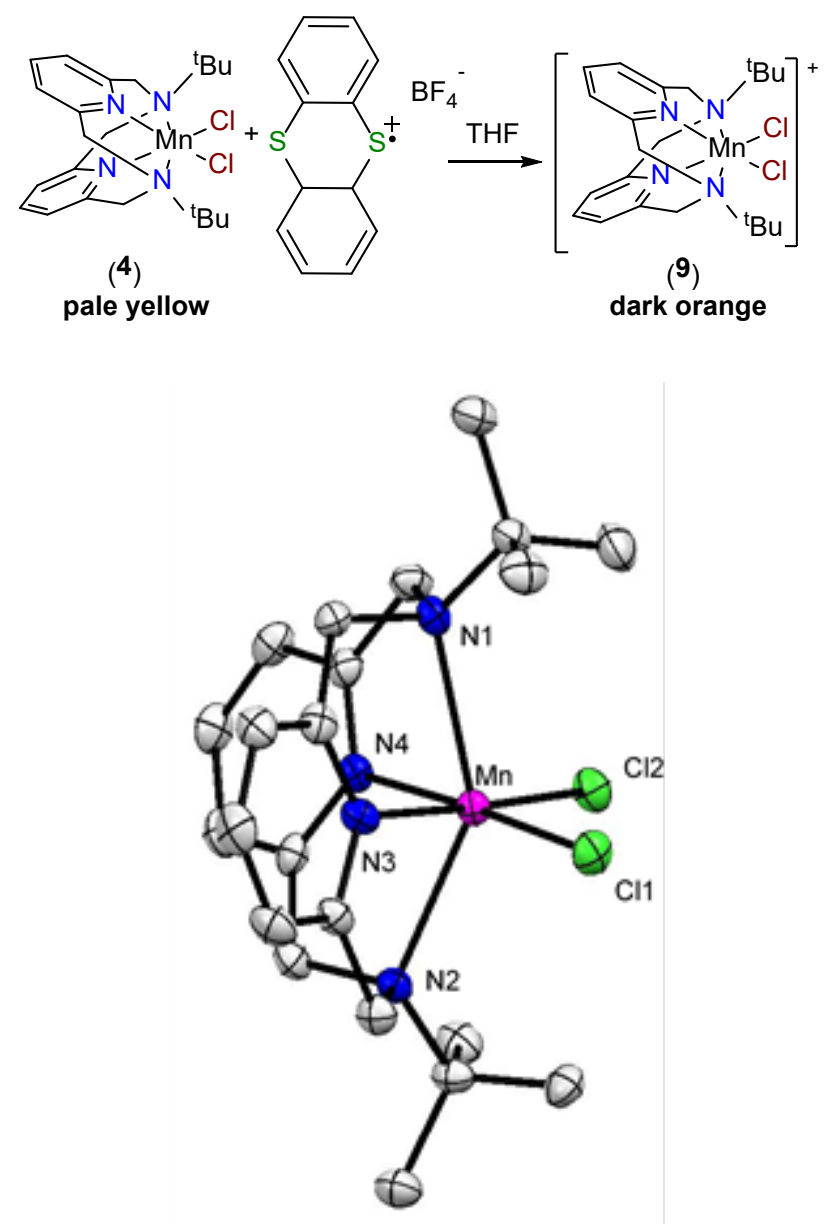

Figure 7. ORTEP diagram of 9 (50\% ellipsoids, hydrogen atoms and $\mathrm{PF}_{6}$ anions are omitted for clarity). Selected bond lengths $(\AA)$ and angles $\left({ }^{\circ}\right)$ : Mn-N1 2.392(3); Mn-N2 2.396(3); Mn-N3 2.028(3); Mn-N4 2.014(4); Mn-Cl1 2.242(1); Mn-Cl2: 2.236(1); N1-Mn-N2 142.8(1); N3-MnN4 85.4(1); Cl1-Mn-Cl2 93.94(4).

In order to delineate the effect of the pyridinophane ligand substituents on the stability of higher oxidation states, we analyzed the $\mathrm{Mn}^{\mathrm{III}} / \mathrm{Mn}^{\mathrm{II}}$ electrochemical data in terms of steric and electronic parameters. While $E_{1 / 2}$ does not correlate well with the steric parameter of the ligand substituent, as measured by the A value (Figure S13), ${ }^{41-42}$ there is a good linear relationship with the Hammett parameter, $\sigma_{\mathrm{p}}$ (Figure 8). ${ }^{43-44}$ This suggests that the donor strength of the 
pyridinophane ligand is the key factor that affecting the stability of the $\mathrm{Mn}$ (III) oxidation state, despite the significant effect of substituent sterics on the molecular structures (Tables 1 and 2).

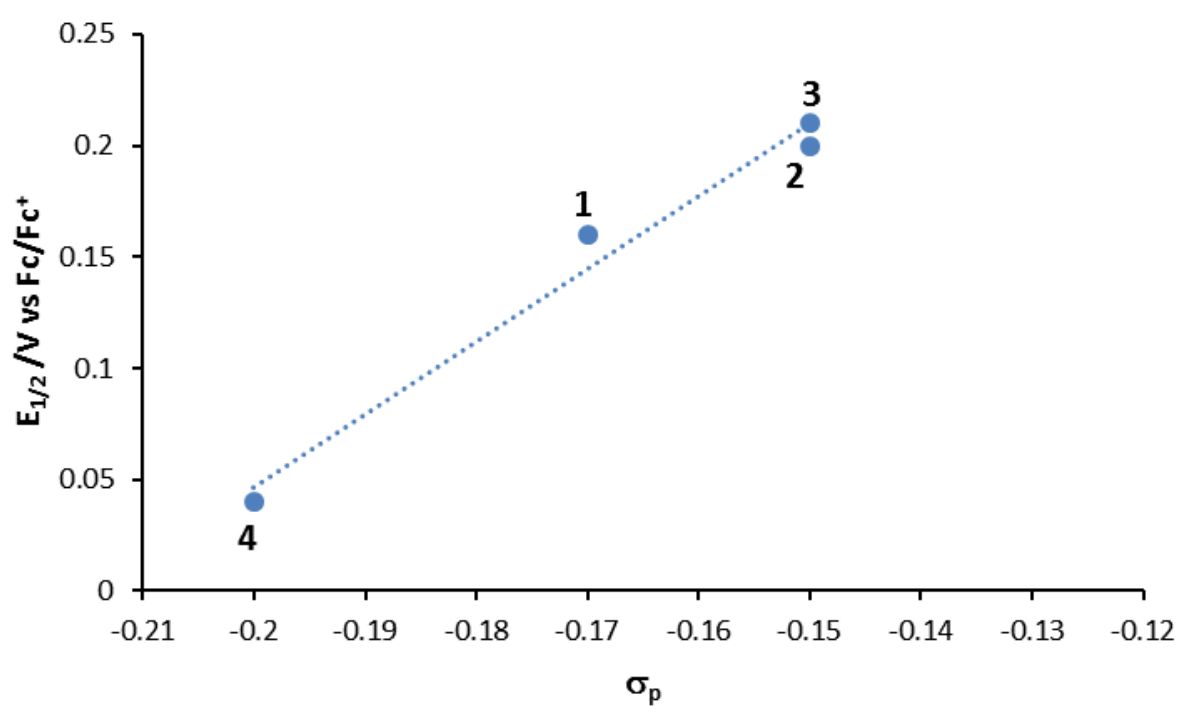

Figure 8. $E_{1 / 2}\left(\mathrm{Mn}^{\mathrm{III}} / \mathrm{Mn}^{\mathrm{II}}\right)$ for $\mathbf{1}$ - $\mathbf{4}$ vs Hammett values $\left(\sigma_{\mathrm{p}}\right)$ of the amine substituents. Plot fits to equation: $y=3.2687 x+0.7, R^{2}=0.9793$.

\section{Catalytic activity in $\mathrm{O}_{2}$ evolution.}

We have previously demonstrated that complex $\mathbf{1}$ is catalytically active towards $\mathrm{H}_{2} \mathrm{O}_{2}$ disproportionation whereas $\left(\mathrm{Py}_{2} \mathrm{~N}^{\mathrm{t}} \mathrm{Bu}_{2}\right) \mathrm{MnCl}_{2}$ is not. ${ }^{10}$ On the other hand, complex 4 is active in electrocatalytic oxidation of $\mathrm{H}_{2} \mathrm{O}$ to $\mathrm{O}_{2}$ whereas $\mathbf{1}$ is not. ${ }^{9}$ To better delineate the effect of pyridinophane ligand substitution on these catalytic reactions, we investigated reactivity of $\mathbf{2}$ and 3 towards both $\mathrm{H}_{2} \mathrm{O}_{2}$ disproportionation and $\mathrm{H}_{2} \mathrm{O}$ oxidation.

The catalytic reactivity towards $\mathrm{H}_{2} \mathrm{O}_{2}$ disproportionation of complexes $\mathbf{1}-\mathbf{3}$ along with $\left(\mathrm{Py}_{2} \mathrm{NH}_{2}\right) \mathrm{MnCl}_{2}{ }^{9}$ shows that the rate of $\mathrm{O}_{2}$ formation has a clear dependence on the pyridinophane substituent (Figure 9): bulkier substituents significantly slow the rate of reaction, 
with $\mathbf{4}$, which has the bulkiest substituents, being inactive. The linear relationship between $\log (k)$ and the steric parameter (A value) ${ }^{41}$ confirms that the ligand bulkiness plays in controlling the rate of catalysis (Figure 8 , inset).

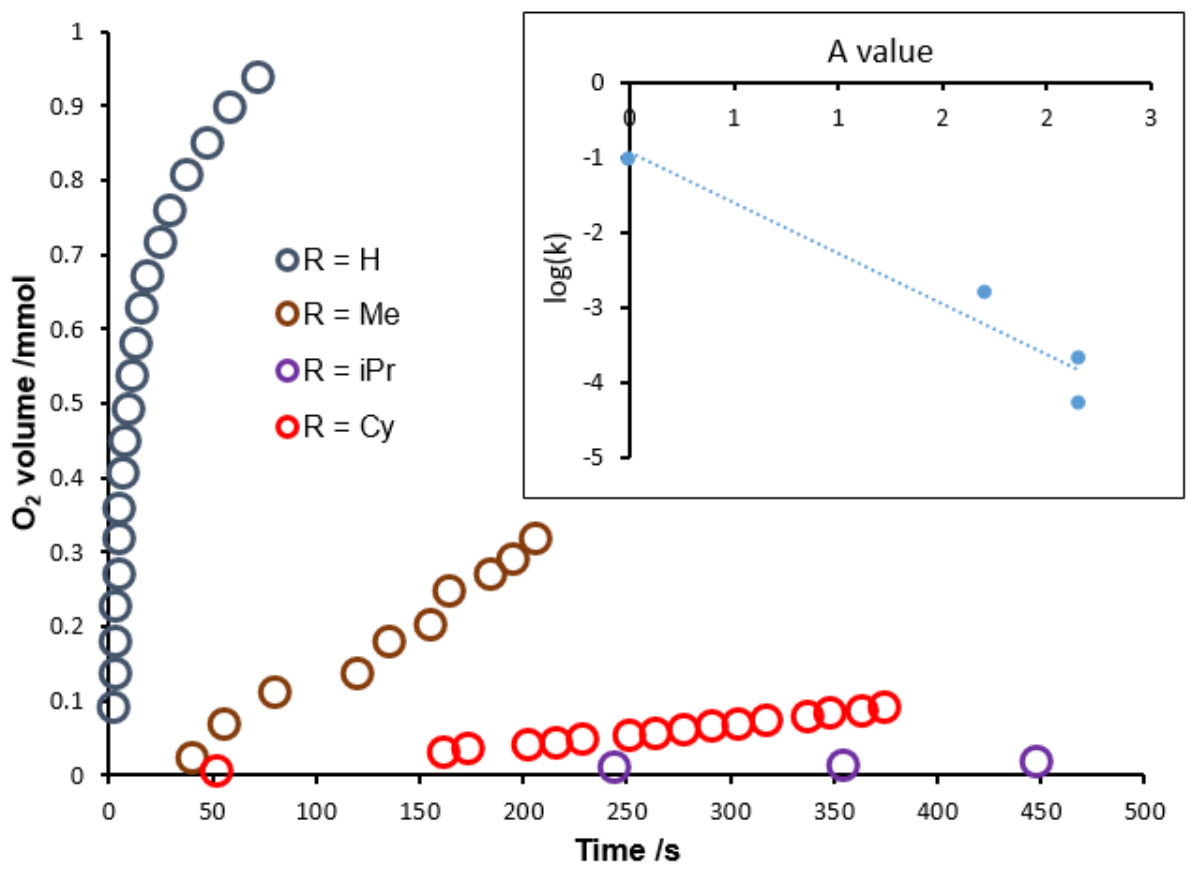

Figure 9. Oxygen formation by $\mathrm{H}_{2} \mathrm{O}_{2}$ disproportionation catalyzed by $\mathrm{Py}_{2} \mathrm{NH}_{2} \mathrm{MnCl}_{2}$ and complexes 1 - 3. Initial conditions: $\left[\left(\mathrm{Py}_{2} \mathrm{NR}_{2}\right) \mathrm{MnCl}_{2}\right]=0.4 \mathrm{mM},\left[\mathrm{H}_{2} \mathrm{O}_{2}\right]=3.1 \mathrm{M}, \mathrm{pH}=7.0,298$ K. Inset: plot of $\log (k)$ vs A value ( $k$ : initial rate of $\mathrm{O}_{2}$ formation). Plot fits to equation: $y=$ $-1.3497 x-0.937, R^{2}=0.9335$.

We have used cyclic voltammetry to investigate the ability of complexes $\mathbf{1}^{9}-\mathbf{4}$ towards electrocatalytic $\mathrm{H}_{2} \mathrm{O}$ oxidation (Figure 10). The cyclic voltammogram of $\mathbf{2}$ and $\mathbf{3}$ toward $\mathrm{H}_{2} \mathrm{O}$ oxidation exhibits either a large oxidation wave (complex 2) or enhanced current (complex 3 ), suggesting both are active toward $\mathrm{H}_{2} \mathrm{O}$ oxidation at similar overpotential to $4 .{ }^{45}$ Similarly to $\mathrm{H}_{2} \mathrm{O}_{2}$ disproportionation, the activity of $\left(\mathrm{Py}_{2} \mathrm{NR}_{2}\right) \mathrm{MnCl}_{2}$ toward electrochemical $\mathrm{H}_{2} \mathrm{O}$ oxidation also depends on the size of the pyridinophane ligand, however there is no simple relationship 
between the substituent size and any electrochemical parameter (e.g., onset potential or peak current).

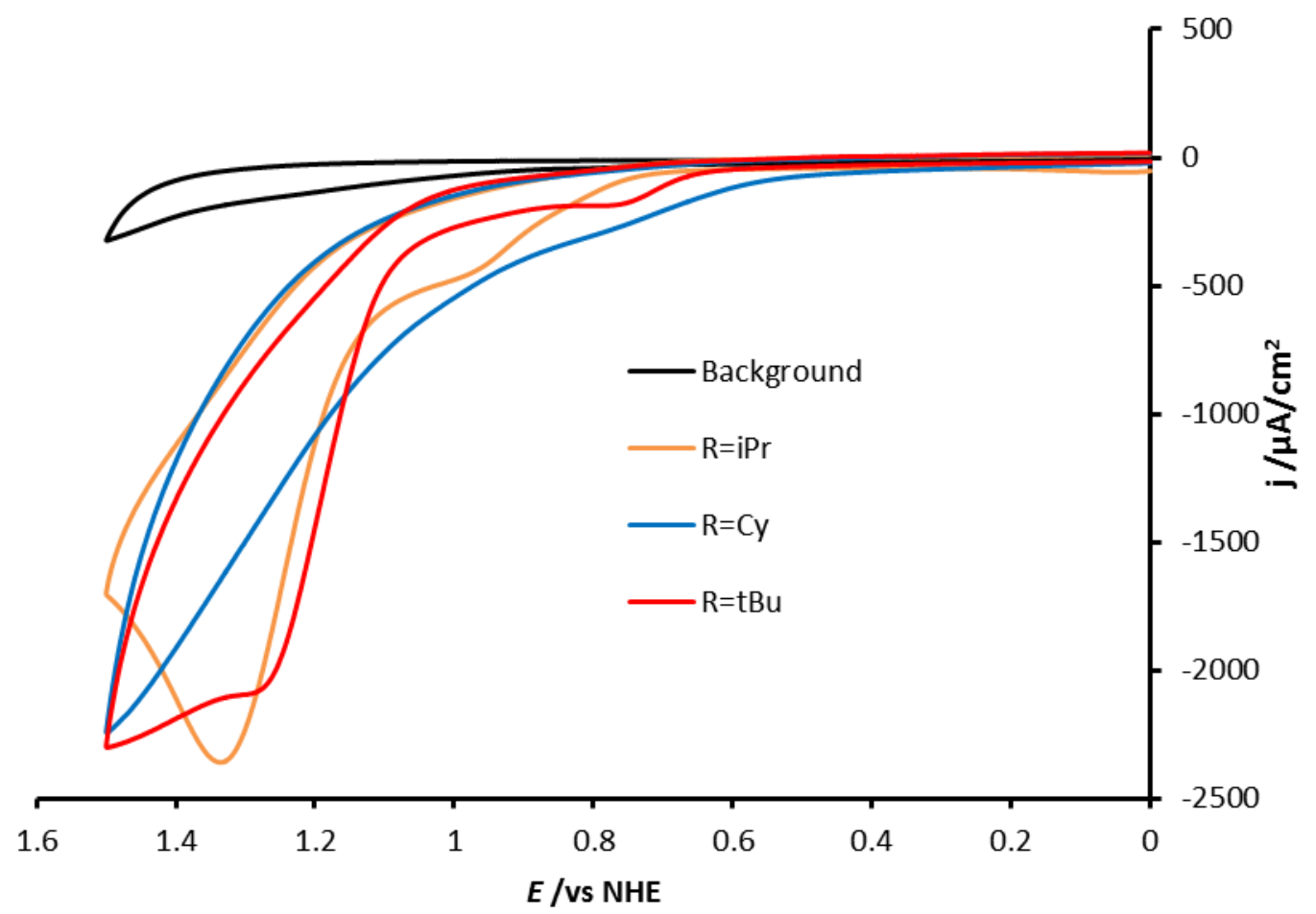

Figure 10. Cyclic voltammogram of solution without $\left(\mathrm{Py}_{2} \mathrm{NR}_{2}\right) \mathrm{MnCl}_{2}$ complex (black), and with $\mathrm{Mn}(\mathrm{II})$ complexes at $0.5 \mathrm{mM}$ : $\mathrm{R}={ }^{\mathrm{i}} \operatorname{Pr}_{2}$ (2) (orange), $\mathrm{R}=\mathrm{Cy}(3)$ (blue), $\mathrm{R}={ }^{\mathrm{t}} \mathrm{Bu}$ (4) (red), all at $\mathrm{pH}$ $=12.2, \mathrm{GC}$ electrode, $50 \mathrm{mM} \mathrm{KOTf}$, scan rate $=100 \mathrm{mV} / \mathrm{s}$.

Previous computational investigations into the mechanism of catalytic $\mathrm{H}_{2} \mathrm{O}$ oxidation by 4 implicate the formation of high valent Mn-oxo/oxyl species as precursors to O-O coupling and consequent $\mathrm{O}_{2}$ generation. ${ }^{28-29}$ Since the overpotential for water oxidation depends on the accessibility of these species, the pyridinophane substituents may be expected to play an important role in the energetics of catalysis. Using the $\mathrm{Mn}^{\mathrm{II}} / \mathrm{Mn}^{\mathrm{II}}$ couple as an indicator for the accessibility of higher oxidation states, it is notable that there is no relationship between the onset of catalytic activity and $E_{1 / 2}\left(\mathrm{Mn}^{\mathrm{III}} / \mathrm{Mn}^{\mathrm{II}}\right)$, and consequently the donor strength of the ligand 
(c.f. Figure 8). For example, despite complex 4 having the lowest $E_{1 / 2}\left(\mathrm{Mn}^{\mathrm{III}} / \mathrm{Mn}^{\mathrm{II}}\right)$ (by over 0.1 $\mathrm{V})$, the onset of catalysis is similar to that observed for complexes $\mathbf{2}$ and $\mathbf{3}$. Moreover, although $E_{1 / 2}\left(\mathrm{Mn}^{\mathrm{III}} / \mathrm{Mn}^{\mathrm{II}}\right)$ for $\mathbf{1}$ is at a lower potential than for $\mathbf{2}$ or $\mathbf{3}$, this complex shows no evidence for $\mathrm{H}_{2} \mathrm{O}$ oxidation catalysis. ${ }^{9}$ Thus, the activity of these complexes for electrocatalytic water oxidation cannot be related to simple electronic effects.

Despite the apparent lack of electronic effect of ligand donor strength on water oxidation catalysis, it is evident that only the complexes with smaller pyridinophane ligand substituents, i.e. $\left(\mathrm{Py}_{2} \mathrm{NH}_{2}\right) \mathrm{MnCl}_{2}$ and $\mathbf{1}$, are not catalytically active. However, there is no simple trend that relates catalytic activity to the size of the pyridinophane ligand. Thus, although there appears to be a steric threshold for achieving water oxidation electrocatalysis, the catalytic activity of $\left(\mathrm{Py}_{2} \mathrm{NR}_{2}\right) \mathrm{MnCl}_{2}$ complexes cannot be related to simple steric or electronic factors.

\section{Summary and Conclusions}

A series of $\mathrm{Mn}(\mathrm{II})$ and $\mathrm{Mn}(\mathrm{III})$ complexes bearing pyridinophane ligands with different substituents have been prepared and characterized. While a relationship between the size of the pyridinophane amine substituent and the metrical parameters of the $\mathrm{Mn}(\mathrm{II})$ complexes $(\mathbf{1}-\mathbf{4})$ was observed, no such trend was observed for the structures of the Jahn-Teller distorted Mn(III) complexes $(\mathbf{5}-\mathbf{8})$. HFEPR spectroscopy of $\mathbf{6}$ was characteristic for six-coordinate high-spin $\mathrm{Mn}(\mathrm{III})$, in terms of having a negative $D$ value of modest magnitude: $D=-3.79 \mathrm{~cm}^{-1}$, with slight rhombicity $|E / D|=0.04$. Computational investigation at an ab initio level of theory are fully consistent with experiment, providing calculated $D$ values in the range from -3.8 to $-4.0 \mathrm{~cm}^{-1}$. The cyclic voltammograms of the $\mathrm{Mn}(\mathrm{II})$ complexes reveal reversible $\mathrm{Mn}^{\mathrm{III}} / \mathrm{Mn}^{\mathrm{II}}$ redox couples, which has been synthetically confirmed through the synthesis and characterization of 
$\left[\left(\mathrm{Py}_{2} \mathrm{~N}^{t} \mathrm{Bu}_{2}\right) \mathrm{MnCl}_{2}\right] \mathrm{BF}_{4}(9)$. The stability of the $\mathrm{Mn}(\mathrm{III})$ state was found to be directly related to the donor strength of pyridinophane ligand substituents.

The donor strength of the ligand is critical for accessing higher Mn oxidation states, and thus suggests that the pyridinophane ligand platform is in general terms well suited for $\mathrm{H}_{2} \mathrm{O} / \mathrm{H}_{2} \mathrm{O}_{2}$ activation catalysis. What is also apparent, however, is that rather than further tuning the donor properties of this platform, the size of the ligand is also critical, as seen in comparing the catalytic activity of $\mathbf{1}-\mathbf{4}$. In the case of $\mathrm{H}_{2} \mathrm{O}_{2}$ disproportionation, the rate of reaction decreases as the size of the $\mathrm{R}$ group increases, while electrocatalytic water oxidation was observed for complexes only having bulky ligand substituents. The relative insensitivity to electronic effects bodes well for similarly converting other $\mathrm{H}_{2} \mathrm{O}_{2}$ disproportionation catalysts to water oxidation catalysts through increase in ligand bulk, similar to the tuning achieved of the organic substituents in widely used ligands such as phosphines, pyrazolyl borates, and N-heterocyclic carbenes. 


\section{Experimental}

\section{General Considerations}

All anaerobic manipulations, including non-aqueous electrochemical measurements, were performed under nitrogen atmosphere by using standard Schlenk techniques or in an M. Braun Labmaster glovebox. Glassware was dried at $150{ }^{\circ} \mathrm{C}$ overnight. Organic solvents were purified by the Glass Contour solvent system. Deionized water was used for all aqueous experiments or measurements. ${ }^{1} \mathrm{H}$ NMR data were recorded on a Varian Unity 400 spectrometer (400 MHz) at $22{ }^{\circ} \mathrm{C}$. UV-visible spectra were recorded with an Agilent Cary $60 \mathrm{UV}$-visible spectrometer. High resolution mass spectra were recorded using positive electrospray ionization on a Thermo Electron Corp MAT-95XP spectrometer. Trifluoroacetic acid $\left(\mathrm{CF}_{3} \mathrm{COOH}\right)$ was used as protonation agent for neutral complexes. Solution magnetic susceptibilities were determined by Evans' method. ${ }^{46}$ Electrochemical measurements were recorded on a CHI 600D electrochemical analyzer (CH Instruments). Working electrode: glassy carbon $(\mathrm{GC})$ electrode $\left(3 \times 3 \mathrm{~mm}^{2}, \mathrm{CH}\right.$ Instruments). Auxiliary electrode: platinum wire (Alfa Aesar, 99.99\%). Pseudo-reference electrode: Ag wire (Alfa Aesar, 99.99\%). The final redox potentials were calculated by comparing the measured potentials with $E_{1 / 2}$ of $\mathrm{Fc} / \mathrm{Fc}^{+}$in the same solution. The reproducibility of all cyclic voltammetry experiments are verified by several repeat scans.

\section{Synthesis of compounds}

The compounds of 2,6-bis(bromomethyl)pyridine, ${ }^{47} N, \quad N^{\prime}$-di-methyl-2,11-diaza[3,3](2,6)pyridinophane $\left(\mathrm{Py}_{2} \mathrm{NMe}_{2}\right), 2,11$-diaza[3,3](2,6)-pyridinophane $\left(\mathrm{Py}_{2} \mathrm{NH}_{2}\right),{ }^{48} \mathbf{1}$ and 5, ${ }^{17} N, N^{\prime}$-diisopropyl-2,11-diaza[3,3](2,6)-pyridinophane $\left(\mathrm{Py}_{2} \mathrm{~N}^{\mathrm{i}} \mathrm{Pr}_{2}\right)^{38}, \mathbf{1}^{\prime},{ }^{10} \mathbf{4}^{\prime},{ }^{9}$ and thianthrenyl cation $\left(\mathrm{Th} \bullet^{+} \mathrm{BF}_{4}^{-}\right)^{49}$ were prepared according to literature procedures. All other compounds were obtained from commercial suppliers and used as received. 
Preparation of $\mathbf{P y} \mathbf{y}_{2} \mathbf{N}^{t} \mathbf{B u} \mathbf{u}_{2}$ ligand. The synthesis of $N, N^{\prime}$-di-tert-butyl-2, 11-diaza[3,3](2,6)pyridinophane $\left(\mathrm{Py}_{2} \mathrm{~N}^{t} \mathrm{Bu}_{2}\right)$ was adapted from reported literature procedures. ${ }^{50}$ tert-Butylamine (7.61 mL, $71 \mathrm{mmol}, 9$ eq) was added to a solution of 2, 6-dibromomethyl pyridine (2.1 g, 7.92 $\mathrm{mmol})$ in benzene $(200 \mathrm{~mL})$ and water $(500 \mathrm{~mL})$ at ambient temperature. The resulting solution of mixture was heated at $80{ }^{\circ} \mathrm{C}$ overnight then cooled to room temperature. After spontaneous separation, the organic phase was washed with water $(2 \times 100 \mathrm{~mL})$ and dried over sodium sulfate. The solvent were then removed by vacuum evaporation to yield a sticky solid. After washing with hexane, the solid was chromatographed (column, $\mathrm{SiO}_{2}$ ) by eluting with dichloromethane containing increasing concentrations of triethylamine (0-5\%) to yield $\mathrm{Py}_{2} \mathrm{~N}^{t} \mathrm{Bu}_{2}$ as a white solid $(150 \mathrm{mg}, 11 \%)$. The spectral properties are identical to those reported in the literature. ${ }^{50}{ }^{1} \mathrm{H}$ NMR $\left(\mathrm{CDCl}_{3}, 400 \mathrm{MHz}\right): \delta 1.37\left(18 \mathrm{H}, \mathrm{s}, \mathrm{CH}_{3}\right) ; 3.97$ (8H, s, $\left.\mathrm{PyCH}_{2}\right) ; 6.68-6.76$ (4H, d, 3, 5-Py H) and 6.91-7.27 (2H, m, 4-Py H).

Preparation of $\mathrm{Py}_{2} \mathrm{NCy}_{2}$ ligand. $\mathrm{Py}_{2} \mathrm{NCy}_{2}$ is prepared according to a modified procedure modified from the literature. ${ }^{16}$ A $125 \mathrm{~mL}$ RB flask was charged with $\mathrm{Py}_{2} \mathrm{NH}_{2}(0.048 \mathrm{~g}, 0.50$ mmol), cyclohexylbromide ( $3 \mathrm{~mL}, 50 \mathrm{mmol}, 100 \mathrm{eq}$ ), anhydrous $\mathrm{K}_{2} \mathrm{CO}_{3}(1.38 \mathrm{~g}, 10 \mathrm{mmol}, 20$ eq) and dry $\mathrm{MeCN}(50 \mathrm{~mL})$. The reaction was heated at reflux under a nitrogen atmosphere for 7 days. The solution was then cooled to RT and the solvent was removed under reduced pressure. The residue was suspended in $\mathrm{CH}_{2} \mathrm{Cl}_{2}(50 \mathrm{~mL})$ and then washed with $1 \mathrm{M} \mathrm{NaOH}(2 \times 50 \mathrm{~mL})$ solution and water $(2 \times 50 \mathrm{~mL})$. The $\mathrm{CH}_{2} \mathrm{Cl}_{2}$ layer was isolated, dried over anhydrous $\mathrm{MgSO}_{4}$, evaporated, and further dried under vacuum to give an off-white powder $(0.56 \mathrm{~g}, 69 \%)$. The spectra properties are identical to those reported in the literature. ${ }^{16}$

Preparation of $\left(\mathrm{Py}_{2} \mathbf{N R}_{2}\right) \mathbf{M n C l}_{2}$ complexes. Complexes 2, 3, 4 were prepared by adding $\mathrm{MnCl}_{2}$ to a stirred solution of $\mathrm{Py}_{2} \mathrm{NR}_{2}$ ligand in $\mathrm{MeCN}$. After stirring overnight at room 
temperature, $\left(\mathrm{Py}_{2} \mathrm{NR}_{2}\right) \mathrm{MnCl}_{2}$ was obtained as pale yellow solid after removing the solvent under vacuum. Crystals suitable for single crystal X-ray diffraction were directly obtained by slow diffusion of diethyl ether into $\mathrm{MeCN}$ solutions of the complexes. Yields for 2: $70 \%, 3: 66 \%, 4$ : $58 \%$. The complexes were characterized in MeCN solution by HRMS (ESI): calcd for ( $\left.\mathrm{Py}_{2} \mathrm{NR}_{2}\right) \mathrm{MnCl}_{2}$ complexes: 2: $\left(\mathrm{C}_{20} \mathrm{H}_{28} \mathrm{ClMnN}_{4}\right) \mathrm{m} / \mathrm{z}: 414.1383$ ([M-Cl] $\left.]^{+}\right)$; found: 414.1366; 3: $\left(\mathrm{C}_{26} \mathrm{H}_{36} \mathrm{MnN}_{4} \mathrm{CF}_{3} \mathrm{COO}\right) \quad \mathrm{m} / \mathrm{Z}: \quad 572.2171 \quad\left(\left[\mathrm{M}-\mathrm{CF}_{3} \mathrm{COO}\right]^{+}\right) ; \quad$ found: $\quad 572.2167 ; \quad 4:$ $\mathrm{C}_{22} \mathrm{H}_{32} \mathrm{MnN}_{4} \mathrm{CF}_{3} \mathrm{COO} \mathrm{m} / \mathrm{z}: 520.1858\left(\left[\mathrm{M}-\mathrm{CF}_{3} \mathrm{COO}\right]^{+}\right)$; found: 520.1860 .

Preparation of $\mathbf{2}^{\prime}$. Complex $\mathbf{2}^{\prime}$ was synthesized by treating $2(23 \mathrm{mg}, 0.05 \mathrm{mmol})$ with $\mathrm{TlPF}_{6}$ (35 $\mathrm{mg}, 0.1 \mathrm{mmol})$ in acetonitrile $(10 \mathrm{~mL})$. After stirring at room temperature overnight, the reaction mixture was filtered and the solvent was removed under reduced pressure to yield an off-white powder (44 mg, 60\%).

Preparation of 6, 7, 8: Under anaerobic conditions, $\mathbf{2}^{\prime}, \mathbf{3}^{\prime}, \mathbf{4}^{\prime}$ (0.045 mmol, 1 eq) were mixed with $\mathrm{XeF}_{2}(0.048 \mathrm{mmol}, 1.05 \mathrm{eq})$ in acetonitrile $(10 \mathrm{~mL})$. The mixtures were stirred overnight to yield red-brown solutions which were concentrated under reduced pressure to $c a$. $5 \mathrm{~mL}$. Redorange crystals of $\mathbf{6 , 8}$ suitable for single crystal X-ray diffraction were obtained by slow diffusion of diethyl ether into these solutions. Yields for 6: $40 \%, 7: 30 \%, 8$ : $45 \%$. Complexes were characterized in $\mathrm{MeCN}$ solution by HRMS (ESI): calcd for $\left[\left(\mathrm{Py}_{2} \mathrm{NR}_{2}\right) \mathrm{MnF}_{2}\right]^{+}$complexes: 6 : $\left(\mathrm{C}_{20} \mathrm{H}_{28} \mathrm{MnN}_{4} \mathrm{~F}_{2}\right) \mathrm{m} / \mathrm{z}: 417.1663\left([\mathrm{M}]^{+}\right)$; found: 417.1665; 7: $\left(\mathrm{C}_{26} \mathrm{H}_{36} \mathrm{MnN}_{4} \mathrm{~F}_{2}\right) \mathrm{m} / \mathrm{z}: 497.2289$ ([M] $]^{+}$); found: $497.2282 ; 8: \mathrm{C}_{22} \mathrm{H}_{32} \mathrm{MnN}_{4} \mathrm{~F}_{2} \mathrm{~m} / \mathrm{z}: 445.1975$ ([M] $]^{+}$); found: 445.1979. UV-vis $\left(\mathrm{CH}_{3} \mathrm{CN}\right): \lambda_{\max }\left(\varepsilon / \mathrm{L} \cdot \mathrm{mol}^{-1} \cdot \mathrm{cm}^{-1}\right)=468(92), 489(89) \mathrm{nm}$ for $\mathbf{2} ; 468(133), 494(130) \mathrm{nm}$ for 3; 465 (134), 501 (189) nm for 4.

Synthesis of 6 from $\mathrm{MnF}_{3}$. The $\mathrm{Py}_{2} \mathrm{~N}^{\mathrm{i}} \mathrm{Pr}_{2}$ ligand $(20 \mathrm{mg}, 0.05 \mathrm{mmol}$ ) was added to a slurry of $\mathrm{MnF}_{3}(5.6 \mathrm{mg}, 0.05 \mathrm{mmol})$ in $\mathrm{MeOH}(15 \mathrm{~mL})$. The mixture was then warmed at $50{ }^{\circ} \mathrm{C}$ until the 
yellow-cloudy solution became clear brown (ca. 4 h). Aqueous $\mathrm{NaPF}_{6}(5 \mathrm{~mL}, 16.8 \mathrm{mg}, 0.1$ mmol) was then added to the solution, which was dried under reduced pressure to give a brown residue. The product was extracted into $10 \mathrm{~mL}$ dichloromethane and the solvent was removed under reduced pressure to give 6 as a brown powder (10 mg, 30\%). An orange crystal for single crystal X-ray diffraction was obtained through slow diffusion of pentane into a concentrated dichloromethane solution at ambient temperature. The spectra properties are identical to the characterizations of $\mathbf{6}$ prepared through $\mathrm{XeF}_{2}$ fluorination described above.

Preparation of 9. Under anaerobic conditions, $\mathrm{Th}^{\circ}{ }^{+} \mathrm{BF}_{4}^{-}(19 \mathrm{mg}, 0.06 \mathrm{mmol})$ was added to a solution of $\left(\mathrm{Py}_{2} \mathrm{~N}^{\mathrm{t} B u}\right) \mathrm{MnCl}_{2}(25 \mathrm{mg}, 0.05 \mathrm{mmol})$ in THF $(15 \mathrm{~mL})$. The reaction was further stirred at room temperature overnight until the yellow slurry change to red, filtered through Celite and washed with THF ( $5 \mathrm{~mL})$ to afford a dark orange solid. Dark orange crystals of 9 suitable for single crystal X-ray diffraction were obtained by slow diffusion of diethyl ether into its acetonitrile solution. Yield: $11 \mathrm{mg}, 40 \%$. Complexes 9 was characterized in MeCN solution by HRMS (ESI): calcd for $\mathrm{C}_{22} \mathrm{H}_{32} \mathrm{Cl}_{2} \mathrm{MnN}_{4} \mathrm{~m} / \mathrm{z}: 477.1385$ ([M] $]^{+}$); found: 477.1381 . UV-vis $\left(\mathrm{CH}_{3} \mathrm{CN}\right): \lambda \max \left(\varepsilon / \mathrm{L} \cdot \mathrm{mol}^{-1} \cdot \mathrm{cm}^{-1}\right)=494(255), 518(335) \mathrm{nm}$.

HFEPR spectroscopy. HFEPR measurements were made using a spectrometer described elsewhere. ${ }^{51}$ The samples were investigated both as loose microcrystalline powders and compressed into pellets. HFEPR spectra were simulated with the program SPIN, from A. Ozarowski, ${ }^{52}$ using a standard spin Hamiltonian for $S=2,{ }^{53}$ with only second order ZFS terms.

Ligand-Field Theory. The programs Ligfield, from J. Bendix,${ }^{54}$ and DDN and DDNFIT,,${ }^{55}$ from J. Telser, were used for LFT analysis of the Mn(III) complexes as described in Supporting Information. 
Quantum Chemical Theory. Gaussian09 ${ }^{56}$ software was used for B3LYP $\mathrm{LP}^{57-60} / 6-311 \mathrm{G}^{* 61-63}$ geometry optimizations of $\mathrm{Mn}(\mathrm{III})$ complexes and production of particular MOs shown in Supporting Information. The ORCA program package by F. Neese and co-workers (version 3.0.0 ${ }^{64-65}$ was used for calculation of spin Hamiltonian parameters, specifically employing CASSCF, ${ }^{18,20-23}$, NEVPT2, ${ }^{24-26}$ and MRCI $^{18,} 20,27$ methods. Further details are given in Supporting Information.

Acknowledgment: S.X. and J.M.S. acknowledge funding from Indiana University and the NSF (CHE-1566258). A portion of this work was performed at the National High Magnetic Field Laboratory, which is supported by National Science Foundation Cooperative Agreement No. DMR-1157490 and the State of Florida. We thank Dr. Andrew Ozarowski for his EPR fit and simulation software SPIN. M.B and L.B. acknowledge support from the Slovak Science and Technology Assistance Agency under the contract Nos. APVV-15-0053 and APVV-15-0079 and by the Slovak Grant Agency VEGA under contract Nos. 1/0598/16 and 1/0416/17. We thank the HPC center at the Slovak University of Technology in Bratislava, which is a part of the Slovak Infrastructure of High Performance Computing (SIVVP Project, ITMS code 26230120002, funded by the European Region Development Funds), for computing facilities.

\section{References:}

1. Blakemore, J. D.; Crabtree, R. H.; Brudvig, G. W., Molecular Catalysts for Water Oxidation. Chem. Rev. 2015, 115 (23), 12974-13005.

2. Meyer, T. J., Chemical approaches to artificial photosynthesis. Acc. Chem. Res. 1989, 22 (5), 163-170.

3. Gray, H. B., Powering the planet with solar fuel. Nat. Chem. 2009, 1 (1), 7-7.

4. Umena, Y.; Kawakami, K.; Shen, J.-R.; Kamiya, N., Crystal structure of oxygenevolving photosystem II at a resolution of $1.9 \AA$. Nature 2011, 473 (7345), 55-60. 
5. Yano, J.; Yachandra, V., Mn ${ }_{4} \mathrm{Ca}$ Cluster in Photosynthesis: Where and How Water is Oxidized to Dioxygen. Chem. Rev. 2014, 114 (8), 4175-4205.

6. $\quad$ Suga, M.; Akita, F.; Hirata, K.; Ueno, G.; Murakami, H.; Nakajima, Y.; Shimizu, T.; Yamashita, K.; Yamamoto, M.; Ago, H.; Shen, J.-R., Native structure of photosystem II at 1.95 $\AA$ Åsolution viewed by femtosecond X-ray pulses. Nature 2015, 517 (7532), 99-103.

7. $\quad$ Kanady, J. S.; Lin, P.-H.; Carsch, K. M.; Nielsen, R. J.; Takase, M. K.; Goddard, W. A.; Agapie, T., Toward Models for the Full Oxygen-Evolving Complex of Photosystem II by Ligand Coordination To Lower the Symmetry of the $\mathrm{Mn}_{3} \mathrm{CaO}_{4}$ Cubane: Demonstration That Electronic Effects Facilitate Binding of a Fifth Metal. J. Am. Chem. Soc. 2014, 136 (41), 14373-14376. 8. $\quad$ Najafpour, M. M.; Renger, G.; Hołyńska, M.; Moghaddam, A. N.; Aro, E.-M.; Carpentier, R.; Nishihara, H.; Eaton-Rye, J. J.; Shen, J.-R.; Allakhverdiev, S. I., Manganese Compounds as Water-Oxidizing Catalysts: From the Natural Water-Oxidizing Complex to Nanosized Manganese Oxide Structures. Chem. Rev. 2016, 116 (5), 2886-2936.

9. Lee, W.-T.; Muñoz, S. B.; Dickie, D. A.; Smith, J. M., Ligand Modification Transforms a Catalase Mimic into a Water Oxidation Catalyst. Angew. Chem. Int. Ed. 2014, 53 (37), 98569859.

10. Lee, W.-T.; Xu, S.; Dickie, D. A.; Smith, J. M., A Robust Mn Catalyst for $\mathrm{H}_{2} \mathrm{O}_{2}$ Disproportionation in Aqueous Solution. Eur. J. Inorg. Chem. 2013, 2013 (22-23), 3867-3873. 11. Signorella, S.; Hureau, C., Bioinspired functional mimics of the manganese catalases. Coord. Chem. Rev. 2012, 256 (11), 1229-1245.

12. $\quad$ Chow, T. W.-S.; Wong, E. L.-M.; Guo, Z.; Liu, Y.; Huang, J.-S.; Che, C.-M., cisDihydroxylation of Alkenes with Oxone Catalyzed by Iron Complexes of a Macrocyclic Tetraaza Ligand and Reaction Mechanism by ESI-MS Spectrometry and DFT Calculations. $J$. Am. Chem. Soc. 2010, 132 (38), 13229-13239.

13. Koch, W. O.; Krüger, H.-J., A Highly Reactive and Catalytically Active Model System for Intradiol-Cleaving Catechol Dioxygenases: Structure and Reactivity of Iron(III) Catecholate Complexes of $N, N^{\prime}$-Dimethyl-2,11-diaza[3.3](2,6)pyridinophane. Angew. Chem. Int. Ed. 1996, 34 (23-24), 2671-2674.

14. Zheng, B.; Tang, F.; Luo, J.; Schultz, J. W.; Rath, N. P.; Mirica, L. M., Organometallic Nickel(III) Complexes Relevant to Cross-Coupling and Carbon-Heteroatom Bond Formation Reactions. J. Am. Chem. Soc. 2014, 136 (17), 6499-6504.

15. Krüger, H.-J., Spin transition in octahedral metal complexes containing tetraazamacrocyclic ligands. Coord. Chem. Rev. 2009, 253 (19), 2450-2459.

16. Kim, J.; Shin, B.; Kim, H.; Lee, J.; Kang, J.; Yanagisawa, S.; Ogura, T.; Masuda, H.; Ozawa, T.; Cho, J., Steric Effect on the Nucleophilic Reactivity of Nickel(III) Peroxo Complexes. Inorg. Chem. 2015, 54 (13), 6176-6183.

17. Albela, B.; Carina, R.; Policar, C.; Poussereau, S.; Cano, J.; Guilhem, J.; Tchertanov, L.; Blondin, G.; Delroisse, M.; Girerd, J.-J., Synthesis and X-ray Structure of the $\mathrm{Mn}^{\mathrm{II}} \mathrm{Cl}_{2}$ and $\mathrm{Mn}^{\mathrm{III}} \mathrm{F}_{2}$ Complexes of $N, N^{\prime}$-Dimethyl-2,11-diaza[3,3](2,6)pyridinophane. High-Field Electron Paramagnetic Resonance and Density Funtional Theory Studies of the Mn(III) Complex. Evidence for a Low-Lying Spin Triplet State. Inorg. Chem. 2005, 44 (20), 6959-6966.

18. Neese, F., Importance of Direct Spin-Spin Coupling and Spin-Flip Excitations for the Zero-Field Splittings of Transition Metal Complexes: A Case Study. J. Am. Chem. Soc. 2006, $128(31), 10213-10222$.

19. Neese, F., Calculation of the zero-field splitting tensor on the basis of hybrid density functional and Hartree-Fock theory. J. Chem. Phys. 2007, 127 (16), 164112. 
20. Duboc, C.; Ganyushin, D.; Sivalingam, K.; Collomb, M.-N.; Neese, F., Systematic Theoretical Study of the Zero-Field Splitting in Coordination Complexes of Mn(III). Density Functional Theory versus Multireference Wave Function Approaches. J. Phys. Chem. A 2010, 114 (39), 10750-10758.

21. Zein, S.; Neese, F., Ab Initio and Coupled-Perturbed Density Functional Theory Estimation of Zero-Field Splittings in $\mathrm{Mn}^{\mathrm{II}}$ Transition Metal Complexes. J. Phys. Chem. A 2008, 112 (34), 7976-7983.

22. Romain, S.; Duboc, C.; Neese, F.; Rivière, E.; Hanton, L. R.; Blackman, A. G.; Philouze, C.; Leprêtre, J.-C.; Deronzier, A.; Collomb, M.-N., An Unusual Stable Mononuclear Mn ${ }^{\mathrm{III}}$ Bisterpyridine Complex Exhibiting Jahn-Teller Compression: Electrochemical Synthesis, Physical Characterisation and Theoretical Study. Chemistry - A European Journal 2009, 15 (4), 980-988. 23. Maurice, R.; Bastardis, R.; Graaf, C. d.; Suaud, N.; Mallah, T.; Guihéry, N., Universal Theoretical Approach to Extract Anisotropic Spin Hamiltonians. Journal of Chemical Theory and Computation 2009, 5 (11), 2977-2984.

24. Angeli, C.; Cimiraglia, R.; Evangelisti, S.; Leininger, T.; Malrieu, J.-P., Introduction of n-electron valence states for multireference perturbation theory. J. Chem. Phys. 2001, 114 (23), 10252-10264.

25. Angeli, C.; Cimiraglia, R.; Malrieu, J.-P., N-electron valence state perturbation theory: a fast implementation of the strongly contracted variant. Chem. Phys. Lett. 2001, 350 (3), 297-305. 26. Angeli, C.; Cimiraglia, R.; Malrieu, J.-P., n-electron valence state perturbation theory: A spinless formulation and an efficient implementation of the strongly contracted and of the partially contracted variants. J. Chem. Phys. 2002, 117 (20), 9138-9153.

27. Atanasov, M.; Zadrozny, J. M.; Long, J. R.; Neese, F., A theoretical analysis of chemical bonding, vibronic coupling, and magnetic anisotropy in linear iron(II) complexes with singlemolecule magnet behavior. Chem. Sci. 2013, 4 (1), 139-156.

28. Crandell, D. W.; Xu, S.; Smith, J. M.; Baik, M.-H., Intramolecular Oxyl Radical Coupling Promotes O-O Bond Formation in a Homogeneous Mononuclear Mn-based Water Oxidation Catalyst: A Computational Mechanistic Investigation. Inorg. Chem. 2017, 56 (8), 4436-4446.

29. Li, Y.-Y.; Ye, K.; Siegbahn, P. E. M.; Liao, R.-Z., Mechanism of Water Oxidation Catalyzed by a Mononuclear Manganese Complex. ChemSusChem. 2017, 10 (5), 903-911. 30. Dubinsky-Davidchik, I. S.; Potash, S.; Goldberg, I.; Vigalok, A.; Vedernikov, A. N., Electrophilic Fluorination of Organoplatinum(II) Iodides: Iodine and Platinum Atoms as Competing Fluorination Sites. J. Am. Chem. Soc. 2012, 134 (34), 14027-14032.

31. Brewer, S. A.; Coleman, K. S.; Fawcett, J.; Holloway, J. H.; Hope, E. G.; Russell, D. R.; Watson, P. G., Ruthenium and osmium acyl fluoride complexes. Crystal structure of [OC-613] $\left[\mathrm{RuF}_{2}(\mathrm{CO})_{2}\left(\mathrm{PPh}_{3}\right)_{2}\right] \bullet \mathrm{CD}_{2} \mathrm{Cl}_{2}$. J. Chem. Soc., Dalton Trans. 1995, (7), 1073-1076.

32. Barra, A.-L.; Gatteschi, D.; Sessoli, R.; Abbati, G. L.; Cornia, A.; Fabretti, A. C.; Uytterhoeven, M. G., Electronic structure of manganese(III) compounds from high-frequency EPR spectra. Angew. Chem. Int. Ed. 1997, 36 (21), 2329-2331.

33. Goldberg, D. P.; Telser, J.; Krzystek, J.; Montalban, A. G.; Brunel, L.-C.; Barrett, A. G. M.; Hoffman, B. M., EPR spectra from "EPR-silent" species: high-field EPR spectroscopy of manganese(III) porphyrins. J. Am. Chem. Soc. 1997, 119, 8722-8723.

34. Krivokapic, I.; Noble, C.; Klitgaard, S.; Tregenna-Piggott, P. L. W.; Weihe, H.; Barra, A.-L., Anisotropic hyperfine interaction in the manganese(III) hexaaqua ion. Angew. Chem. Int. Ed. 2005, 44 (23), 3613-3616. 
35. Vallejo, J.; Pascual-Álvarez, A.; Cano, J.; Castro, I.; Julve, M.; Lloret, F.; Krzystek, J.; Munno, G. D.; Armentano, D.; Wernsdorfer, W.; Ruiz-García, R.; Pardo, E., Field-Induced Hysteresis and Quantum Tunneling of the Magnetization in a Mononuclear Manganese(III) Complex. Angew. Chem. Int. Ed. 2013, 52 (52), 14075-14079.

36. Krzystek, J.; Zvyagin, S. A.; Ozarowski, A.; Trofimenko, S.; Telser, J., Tunablefrequency high-field electron paramagnetic resonance. J. Magn. Reson. 2006, 178 (2), 174-183.

37. The SSC contribution is about two times larger $\left(-0.5 \mathrm{~cm}^{-1}\right)$ than dynamic electron correlation effects in the case of the experimental geometry of 5, see Table S5 (Supporting Information).

38. Tang, F.; Qu, F.; Khusnutdinova, J. R.; Rath, N. P.; Mirica, L. M., Structural and reactivity comparison of analogous organometallic $\mathrm{Pd}(\mathrm{III})$ and $\mathrm{Pd}(\mathrm{IV})$ complexes. Dalton Trans. 2012, 41 (46), 14046-14050.

39. Hubin, T. J.; McCormick, J. M.; Collinson, S. R.; Buchalova, M.; Perkins, C. M.; Alcock, N. W.; Kahol, P. K.; Raghunathan, A.; Busch, D. H., New Iron(II) and Manganese(II) Complexes of Two Ultra-Rigid, Cross-Bridged Tetraazamacrocycles for Catalysis and Biomimicry. J. Am. Chem. Soc. 2000, 122 (11), 2512-2522.

40. Connelly, N. G.; Geiger, W. E., Chemical Redox Agents for Organometallic Chemistry. Chem. Rev. 1996, 96 (2), 877-910.

41. Muller, P., Glossary of terms used in physical organic chemistry (IUPAC Recommendations 1994). In Pure Appl. Chem., 1994; Vol. 66, p 1077.

42. Winstein, S.; Holness, N. J., Neighboring Carbon and Hydrogen. XIX. t-Butylcyclohexyl Derivatives. Quantitative Conformational Analysis. J. Am. Chem. Soc. 1955, 77 (21), 5562-5578. 43. Hansch, C.; Leo, A.; Taft, R. W., A survey of Hammett substituent constants and resonance and field parameters. Chem. Rev. 1991, 91 (2), 165-195.

44. Conradie, M. M.; Conradie, J., Electrochemical behaviour of Tris( $\beta$-diketonato)iron(III) complexes: A DFT and experimental study. Electrochimi. Acta. 2015, 152, 512-519.

45. Since rapid decomposition of complexes $\mathbf{2}$ and $\mathbf{3}$ was observed during bulk electrolysis, further investigations into their catalytic activity was not pursued.

46. Baker, M. V.; Field, L. D.; Hambley, T. W., Diamagnetic $\leftrightarrow$ paramagnetic equilibria in solutions of bis(dialkylphosphino)ethane complexes of iron. Inorg. Chem. 1988, 27 (16), 28722876.

47. Baker, W.; Buggle, K. M.; McOmie, J. F. W.; Watkins, D. A. M., 718. Attempts to prepare new aromatic systems. Part VII. $15: 16$-Dihydro-15:16-diazapyrene. The synthesis of di(pyridine-2 : 6-dimethylene). J. Chem. Soc. (Resumed) 1958, (0), 3594-3603.

48. Bottino, F.; Di Grazia, M.; Finocchiaro, P.; Fronczek, F. R.; Mamo, A.; Pappalardo, S., Reaction of tosylamide monosodium salt with bis(halomethyl) compounds: an easy entry to symmetrical N-tosyl aza macrocycles. J. Org. Chem. 1988, 53 (15), 3521-3529.

49. Boduszek, B.; Shine, H. J., Preparation of solid thianthrene cation radical tetrafluoroborate. J. Org. Chem. 1988, 53 (21), 5142-5143.

50. Che, C.-M.; Li, Z.-Y.; Wong, K.-Y.; Poon, C.-K.; Mak, T. C. W.; Peng, S.-M., A simple synthetic route to N,N $\mathrm{N}^{\prime}$-dialkyl-2,11-diaza[3.3](2,6)-pyridinophanes. Crystal structures of $N, N^{\prime}-$ di-tert-butyl-2,11-diaza[3.3](2,6)pyridinophane and its copper(II) complex. Polyhedron. 1994, 13 (5), 771-776.

51. Hassan, A. K.; Pardi, L. A.; Krzystek, J.; Sienkiewicz, A.; Goy, P.; Rohrer, M.; Brunel, L.-C., Ultrawide band multifrequency high-field EMR technique: a methodology for increasing spectroscopic information. J. Magn. Reson. 2000, 142 (2), 300-312. 
52. $\quad$ Ozarowski, A., The Zero-Field-Splitting Parameter $D$ in Binuclear Copper(II) Carboxylates Is Negative. Inorg. Chem. 2008, 47 (21), 9760-9762.

53. Abragam, A.; Bleaney, B., Electron Paramagnetic Resonance of Transition Ions (Oxford Classic Texts in the Physical Sciences). Oxford University Press: Oxford, UK, 2012.

54. Bendix, J., Ligfield. In Comprehensive Coordination Chemistry II, Volume 2:

Fundamentals: Physical Methods, Theoretical Analysis, and Case Studies, Lever, A. B. P., Ed. Elsevier: Amsterdam, 2003; Vol. 2, pp 673-676.

55. Krzystek, J.; Swenson, D. C.; Zvyagin, S. A.; Smirnov, D.; Ozarowski, A.; Telser, J., Cobalt(II) "Scorpionate" Complexes as Models for Cobalt-Substituted Zinc Enzymes: Electronic Structure Investigation by High-Frequency and -Field Electron Paramagnetic Resonance Spectroscopy. J. Am. Chem. Soc. 2010, 132 (14), 5241-5253.

56. Frisch, M. J. T., G. W.; Schlegel, H. B.; Scuseria, G. E.; Robb, M. A.; Cheeseman, J. R.; Montgomery, Jr., J. A.; Vreven, T.; Kudin, K. N.; Burant, J. C.; Millam, J. M.; Iyengar, S. S.; Tomasi, J.; Barone, V.; Mennucci, B.; Cossi, M.; Scalmani, G.; Rega, N.; Petersson, G. A.; Nakatsuji, H.; Hada, M.; Ehara, M.; Toyota, K.; Fukuda, R.; Hasegawa, J.; Ishida, M.; Nakajima, T.; Honda, Y.; Kitao, O.; Nakai, H.; Klene, M.; Li, X.; Knox, J. E.; Hratchian, H. P.; Cross, J. B.; Bakken, V.; Adamo, C.; Jaramillo, J.; Gomperts, R.; Stratmann, R. E.; Yazyev, O.; Austin, A. J.; Cammi, R.; Pomelli, C.; Ochterski, J. W.; Ayala, P. Y.; Morokuma, K.; Voth, G. A.; Salvador, P.; Dannenberg, J. J.; Zakrzewski, V. G.; Dapprich, S.; Daniels, A. D.; Strain, M. C.; Farkas, O.; Malick, D. K.; Rabuck, A. D.; Raghavachari, K.; Foresman, J. B.; Ortiz, J. V.; Cui, Q.; Baboul, A. G.; Clifford, S.; Cioslowski, J.; Stefanov, B. B.; Liu, G.; Liashenko, A.; Piskorz, P.; Komaromi, I.; Martin, R. L.; Fox, D. J.; Keith, T.; Al-Laham, M. A.; Peng, C. Y.; Nanayakkara, A.; Challacombe, M.; Gill, P. M. W.; Johnson, B.; Chen, W.; Wong, M. W.; Gonzalez, C.; Pople, J. A. Gaussian 03, Revision D.01, Revision D.01; Gaussian, Inc.: Wallingford, CT, 2013. 57. Lee, C.; Yang, W.; Parr, R. G., Development of the Colle-Salvetti correlation-energy formula into a functional of the electron density. Phys. Rev. B 1988, 37 (2), 785-789.

58. Becke, A. D., Density-functional Thermochemistry. III. The Role of Exact Exchange. $J$. Chem. Phys. 1993, 98 (7), 5648-5652.

59. Stephens, P. J.; Devlin, F. J.; Chabalowski, C. F.; Frisch, M. J., Ab Initio Calculation of Vibrational Absorption and Circular Dichroism Spectra Using Density Functional Force Fields. J. Phys. Chem. 1994, 98 (45), 11623-11627.

60. Vosko, S. H.; Wilk, L.; Nusair, M., Accurate spin-dependent electron liquid correlation energies for local spin density calculations: a critical analysis. Canadian Journal of Physics 1980, 58 (8), 1200-1211.

61. Krishnan, R.; Binkley, J. S.; Seeger, R.; Pople, J. A., Self-consistent molecular orbital methods. XX. A basis set for correlated wave functions. J. Chem. Phys. 1980, 72 (1), 650-654. 62. McLean, A. D.; Chandler, G. S., Contracted Gaussian basis sets for molecular calculations. I. Second row atoms, $Z=11-18$. J. Chem. Phys. 1980, 72 (10), 5639-5648.

63. Wachters, A. J. H., Gaussian Basis Set for Molecular Wavefunctions Containing ThirdRow Atoms. J. Chem. Phys. 1970, 52 (3), 1033-1036.

64. Neese, F. ORCA - an ab initio, Density Functional and Semiempirical Program Package, 3.0.3; Max Planck Institut für Chemische Energiekonversion: Mülheim an der Ruhr, Germany, 2014.

65. Neese, F., The ORCA program system. Wiley Interdisciplinary Reviews: Computational Molecular Science 2012, 2 (1), 73-78. 